\title{
Tecnologia de encapsulamento na área de alimentos: Uma revisão
}

\author{
Encapsulation technology in the food area: A review \\ Tecnología de encapsulación en el área alimentaria: Una revisión
}

Recebido: 18/05/2021 | Revisado: 27/05/2021 | Aceito: 31/05/2021 | Publicado: 14/06/2021

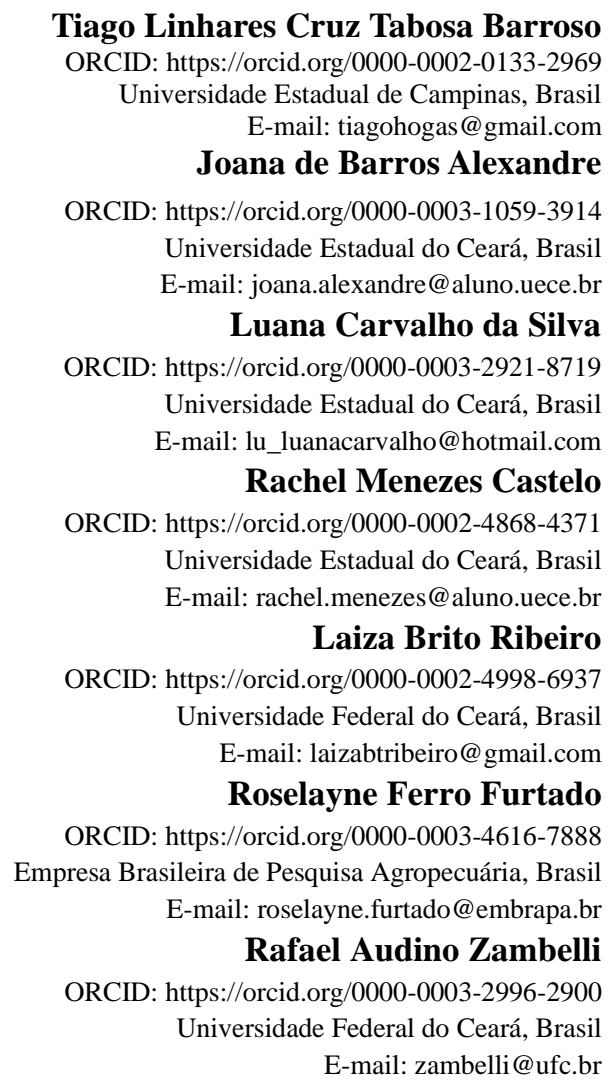

\section{Resumo}

A tecnologia de encapsulamento vem avançando nos últimos anos e adentrando nos diversos segmentos industriais ao proteger substâncias (agentes ativos) de efeitos deletérios que ocasionam a perda de sua função. Baseia-se na proteção de um agente ativo através do condicionamento deste em um invólucro produzido por polímeros. No setor de alimentos podem ser encontradas substâncias encapsuladas incorporadas à matriz alimentícia ou como parte da dinâmica dos processos industriais. O objetivo deste trabalho consistiu em um levantamento bibliográfico, abordando os aspectos de formação, caracterização e aplicação de materiais encapsulados na área de alimentos. Foram elucidados a conceituação do surgimento tecnológico do encapsulamento, os principais métodos para a formação dos particulados: físicos, químicos, físico-químicos e aqueles emergentes na área de estudo. Os agentes ativos mais explorados no setor alimentício também foram apresentados, abordando suas aplicações e propostas inovadoras, levando em consideração o que isso gera de perspectivas futuras para a técnica de encapsulamento, que entre outras finalidades, proporciona melhor aplicação às substâncias que apresentam dificuldades na comercialização em virtude da alta suscetibilidade à fatores extrínsecos que ocasionam a sua deterioração. Dessa forma, se faz necessário incentivar que os estudos de aplicação sejam mais explorados e que isto reflita em soluções que permitam o escalonamento a nível industrial.

Palavras-chave: Agentes ativos; Técnicas de encapsulamento; Indústria de alimentos; Aplicação de partículas.

\begin{abstract}
The encapsulation technology has been advancing in recent years and has entered the various industrial segments by protecting substances (active agents) from deleterious effects that cause the loss of its function. It is based on an active agent protection by conditioning it in a shell produced by polymers. In the food sector, encapsulated substances can be found incorporated into the food matrix or as part of the industrial processes dynamics. The objective of this work
\end{abstract}


consisted of a bibliographic survey, addressing the formation aspects, characterization and encapsulated materials application in the food area. The conceptualization of the technological emergence of encapsulation, the main methods for the particulate's formation: physical, chemical, physical-chemical and those emerging in the study area were elucidated. The most explored active agents in the food sector were also presented, addressing their applications and innovative proposals, taking into account what this generates for future perspectives for the encapsulation technique, which among other purposes, provides better application to substances that have difficulties in commercialization. due to the high susceptibility to extrinsic factors that cause its deterioration. Thus, it is necessary to encourage the application studies to be further explored and that this is reflected in solutions that allow scaling at an industrial level.

Keywords: Active agents; Encapsulation techniques; Food industry; Particle application.

\section{Resumen}

La tecnología de encapsulación ha ido avanzando en los últimos años y se ha introducido en diferentes segmentos industriales con diferentes funciones, incluso de proteger sustancias (agentes activos) de efectos nocivos que provocan pérdida de características fisicoquímicas, químicas o funcionales. Se basa en el acondicionamiento del agente activo en una envoltura de polímeros. En el sector alimentario, las sustancias encapsuladas pueden incorporarse a la matriz alimentaria como parte de la dinámica de los procesos industriales. El objetivo de este trabajo consistió en un levantamiento bibliográfico, abordando los aspectos de formación, caracterización y aplicación de materiales encapsulados en el área de la alimentación. En la conceptualización del surgimiento tecnológico de la encapsulación, se dilucidaron los principales métodos para la formación de partículas: físicos, químicos, físico químicos y los emergentes en el área de estudio. Se fueran aclarados la conceptualización del surgimiento tecnológico de la encapsulación, los principales métodos para la formación de las partículas: físicos, químicos, fisicoquímicos y los emergentes en el área de estudio. También se presentaron los agentes activos más explorados en el sector alimentario, abordando sus aplicaciones y propuestas innovadoras, considerando lo que esto genera desde perspectivas futuras para la técnica de encapsulación que, entre otras finalidades, proporciona una mejor aplicación a sustancias que presentan dificultades de comercialización. Así, es necesario incentivar que los estudios de aplicación sean más explotados y que esto se refleja en soluciones favorables al escalado a nivel industrial.

Palabras clave: Agentes activos; Técnicas de encapsulación; Industria de alimentos; Aplicación de partículas.

\section{Introdução}

Devido à necessidade da proteção de substâncias sensíveis a efeitos deletérios provocados por fatores físicos, químicos e biológicos, para uma utilização mais eficiente, a tecnologia de encapsulamento surge como uma alternativa para a proteção de um material (agente ativo) por meio do revestimento (material de parede) com o uso geralmente de polissacarídeos, proteínas e lipídeos. O encapsulamento além de permitir a proteção do agente ativo frente às condições de deterioração, pode atribuir benefícios de liberação controlada e direcionada para atuação no ponto de interesse no sistema gastrointestinal, transformar o material de interesse em pó, mascarar aromas, melhorar as interações com superfícies ou matrizes de estudo, aumentar a bioacessibilidade ou biodisponibilidade, dentre outras formas as quais os produtos encapsulados vêm sendo explorados e aplicados.

O uso de materiais encapsulados tem sido objeto de estudo e de aplicações a nível industrial (Saifullah, Shishir, Ferdowsi, Rahman \& Vuong, 2019), englobando os setores de fármacos, cosméticos, produtos de limpeza, tecnologia, têxtil e de alimentos. Inicialmente, as pesquisas foram voltadas para as análises de condições otimizadas de formação de micropartículas e nanopartículas, caracterização, liberação e armazenamento, já atualmente observa-se um maior número de testes de aplicação em produtos.

As técnicas de encapsulamento estão sendo apresentadas como alternativas a serem exploradas a fim de contornar problemas na veiculação de ingredientes ativos em alimentos (Favaro-Trindade, Pinho \& Rocha, 2008), no uso de materiais encapsulados desde a inclusão direta em matriz alimentícia (Moura, et al., 2019; Oliveira, et al., 2020; Jiang \& Zhu, 2019; Rutz, et al., 2017), como também estudos que aplicam a técnica de encapsulamento em processos na indústria (ChalcoSandoval, Fabra, López-Rubio \& Lagaron, 2017; Kailasapathy \& Lam, 2005; Kamanina, Lavrora, Arlyapov, Alferov \& Ponamoreva, 2016; Rahim, et al., 2013), como parte integrante das operações para obtenção de um produto acabado. A 
vantagem desse tipo de procedimento é que permite trabalhar com materiais que são susceptíveis aos diversos processos de degradação, viabilizando a ação de agentes ativos. Na indústria já se observam alguns casos, como a Firmenichß que comercializa aromas encapsulados ou a Tiarajuß com óleos de linhaça dourada, peixe, prímula, entre outros encapsulados.

Entre os produtos que despertam interesse para serem encapsulados para fins alimentícios, destacam-se os compostos bioativos, corantes, óleos, probióticos e enzimas, que serão abordados nos tópicos seguintes. Esses materiais são conhecidos por apresentarem sensibilidade a algumas condições ambientais, como temperatura, luz, oxigênio, pressão, além do ataque microbiano, reações químicas, bioquímicas e enzimáticas (Saifullah, et al., 2019; Sharma, Cheng, Bhattacharya \& Chakkaravarthi, 2019; Valldeperas, et al., 2019; Wen, Zong, Linhardt, Feng \& Wu, 2017). Em estudo desenvolvido por Comunian, Silva, Moraes \& Favaro-Trindade, 2020) pode-se observar que os resultados encontrados apresentaram o dobro da resistência oxidativa para a mistura dos óleos de buriti e pequi quando encapsulado. Já na pesquisa desenvolvida por Mörschbächer, Volpato e Souza (2016) onde utilizaram a imobilização da $\beta$-galactosidase e obtiveram eficiência de $72 \%$ da clivagem da lactose em soro de leite, gerando ganhos expressivos para o processo.

Os exemplos citados são algumas formas na qual a tecnologia de encapsulamento auxilia nos processos industriais e atribuem efeitos tecnológicos, sensoriais e nutricionais aos alimentos, desde o plantio, como na produção de bioherbicidas (Taban, Saharkhiz \& Khorram, 2020) ao alimento processado, associado à redução de custos ao setor fabril e a crescente preocupação dos consumidores em produtos mais nutritivos e funcionais.

As populações começaram a tomar consciência da relação existente de uma dieta com inclusão de bioativos a uma boa saúde o que levanta a necessidade de aumentar a estabilidade desses compostos em alimentos processados e a sua adequação técnica dentro de operações da produção industrial, como também solucionar problemas de solubilidade e aumento da permeabilidade nas membranas gástricas e intestinais, o que garante maior absorção, a qual estudos em encapsulamento procuram solucionar mantendo a qualidade e a aceitação sensorial do produto (Waterhouse \& Sun-Waterhouse, 2019).

Dessa forma, este trabalho consiste em uma revisão bibliográfica sobre a aplicação da técnica de encapsulamento em alimentos para promover a discussão a respeito de seu uso como tecnologia industrial, além de apresentar conhecimento que possa impulsionar o desenvolvimento de novas formas de aplicações.

\section{Metodologia}

Este trabalho foi elaborado a partir de um levantamento bibliográfico, caracterizando-se como uma revisão narrativa sobre o assunto tecnologia de encapsulamento na área de alimentos. A busca de artigos e trabalhos científicos foi realizada nas bases de dados das plataformas SCIENCE DIRECT, WEB OF SCIENCE, GOOGLE ACADÊMICO e demais fomes úteis na coleta de informações necessárias para compor esta revisão (UNESP, 2015). Para a seleção dos artigos foram estabelecidos alguns critérios como: revistas categorizadas nos Qualis A1, A2, B1 e B2 e trabalhos publicados, principalmente, entre 2017 e 2020 .

\section{Encapsulamento}

A tecnologia de encapsulamento teve origem na década de 1930 quando o pesquisador Barret K. Green a desenvolveu através do método de coacervação e a primeira aplicação em 1954 como técnica inovadora em papel de cópia sem carbono, uma tinta incolor era encapsulada e aplicada sobre uma camada em papel. Após a ruptura das cápsulas através de uma pressão ocorria a liberação da tinta, que ao entrar em contato com o reagente, o qual também era incorporado no papel dava origem a cor, fazendo com que, por exemplo, um lápis escrevendo sobre uma folha sobreposta a outra, o que estivesse escrito na folha superior seria também impresso na folha abaixo (Microencapsulação, 2017; Blenford, 1986). Desde então, outras empresas e 
pesquisadores se interessaram no desenvolvimento de materiais encapsulados/particulados para os mais diversos fins e setores como o têxtil, farmacêutico, alimentício, produtos de limpeza, entre outros.

A idealização da técnica veio da analogia com a membrana plasmática que reveste o citoplasma celular e possui a função de proteção, assim como o controle seletivo do que entra ou sai (Ré, 2000; Suave, et al., 2006). Dessa forma, foi pensado em reproduzir este comportamento utilizando biopolímeros conhecidos que pudessem fazer a proteção de algum material encapsulado e que apenas ocorresse a liberação em condições específicas, como pH, pressão, temperatura e tempo planejado ou o contato com superfícies específicas.

A conceituação do que seria a tecnologia de encapsulamento foi alterada com o tempo em virtude das novas descobertas e funções a qual foram direcionadas. Na década de 70, o encapsulamento era apontado como uma tecnologia de empacotamento que utilizava polímeros para o revestimento de conteúdos para liberação em velocidade e condições préestabelecidas. Em 1993 se utilizava a terminologia de embalagens extremamente pequenas divididas entre o material de parede e núcleo, diferenciando das embalagens convencionais por permitir melhores performances e usos. No ano de 2005 entendeuse que o encapsulamento passou a ser uma nova fonte de ingredientes com propriedades únicas. Atualmente, utiliza-se o encapsulamento para a manutenção e a conservação de diversas macromoléculas, tais como microrganismos, compostos bioativos, enzimas, corantes, etc., protegendo-os das diversas condições de processamento (Microencapsulação, 2017).

Em estudos recentes, Cacciatore et al. (2020) apresentaram o uso de carvacrol, um fenol monoterpenóide com ação antimicrobiana contra patógenos presentes em superfícies de aço inoxidável, que ao ser encapsulado permite o mascaramento de odor e uma liberação controlada do agente ativo. Lu et al. (2020), por sua vez, utilizaram em seu trabalho o método de eletrofiação coaxial, elaborando um tecido capaz de termorregular a temperatura e emitir brilho para uso de profissionais que trabalham no frio e no escuro, a partir da formação de fibras de tecidos constituídas de parafina revestidas de poliacrilonitrila e fósforo. Em estudos na área tecnológica, Hu, J., Zhang, Xiao e Wang (2020) sugeriram que diodos emissores de luz (LED) podem ter repostas melhores com o uso de nanocristais coloidais de perovskita encapsulados em matrizes poliméricas. Belostozky, Bretler, Kolitz-Domb, Grinberg e Margel (2019) realizaram o encapsulamento do óleo de jojoba (Simmondsia chinensis) em microesferas ocas de sílica como material modelo para futuras aplicações em fármacos e cosméticos, uma vez que o óleo possui ação em estabilizar compostos ativos sensíveis, como vitaminas, contra efeitos oxidativos e a degradação a luz UV, podendo ter ação mais eficiente devido ao aspecto de liberação controlada.

Já a aplicação do encapsulamento na área de alimentos representa uma excelente ferramenta para a proteção de materiais sensíveis a alterações ambientais e químicas, atribuindo maior estabilidade física, liberação controlada e permitindo uma melhor adequação às necessidades do consumidor (Aguilera, 2018).

Para entendermos sobre esta linha de estudo e seus conceitos, este tópico da revisão apresentará as denominações de estruturas e classificações dos materiais particulados.

Embora seja possível a obtenção de materiais encapsulados na escala macro $(>5000 \mu \mathrm{m})$ os estudos se concentram mais nos tamanhos micro $(0,2-5000 \mu \mathrm{m})$ e nano $(<0,2 \mu \mathrm{m})$, uma vez que quando se encontram nas escalas mais reduzidas podem apresentar comportamentos biológicos, físicos e químicos diferentes, atribuindo novas funcionalidades e aplicações em consequência do seu tamanho reduzido, além do aumento da biodisponibilidade, solubilidade e aspectos sensoriais da partícula formada (Azeredo, 2005; Souza Simões, et al., 2017).

A estrutura da partícula é dividida em uma matriz que irá encobrir a substância de interesse, sendo está o agente ativo que será revestido. A matriz é também chamada de veículo, material de parede, invólucro, revestimento, membrana e fase externa e o agente ativo, por sua vez, pode ser chamado de material de núcleo, fase/ carga interna e substância de preenchimento (Vinceković, et al., 2017). 
No que concerne a morfologia temos a classificação em núcleo-invólucro (cápsulas verdadeiras) e tipo matricial (esferas), a diferença está que as cápsulas têm um núcleo contínuo e centralizado a qual se concentra o agente ativo revestido pelo material de parede, enquanto as esferas o agente ativo é disperso em uma matriz sem organização definida de uma região uniforme, podendo ser encontrado o agente ativo exposto na superfície, ao qual não vemos na cápsula verdadeira (Azeredo, 2005; Vinceković, et al., 2017).

Contudo, estudos comprobatórios para a classificação do material em cápsula ou esfera não costumam ser realizados e como padronização das expressões utilizados no texto serão adotados os termos partícula, micropartícula e nanopartícula, pois dessa forma é possível englobar as diferentes morfologias do encapsulamento.

\section{Técnicas de Encapsulamento}

Com o entendimento do que seria o processo de encapsulamento e suas definições devemos compreender também que a seleção da técnica a ser utilizada para obter as micropartículas ou nanopartículas é de suma importância. dependendo, portanto, da interação entre o material de núcleo e de parede, se as etapas de processamento são adequadas aos materiais utilizados, a taxa de liberação premeditada, o tamanho das partículas formadas, como também a futura aplicação (Souza Simões, et al., 2017). Nesse tópico procuramos explicar os métodos utilizados tradicionalmente e aqueles mais emergentes na pesquisa, abordando seu funcionamento e características.

De uma forma geral, os métodos são divididos de acordo com seu mecanismo de formação das partículas em físicos (spray drying, liofilização, evaporação de solventes, precipitação de fluídos supercríticos, etc.), químicos (complexação de inclusão molecular, polimerização in situ, etc.) e os físico-químicos (lipossomas, gelificação iônica, emulsificação, coacervação, etc.) (Ozkan, Franco, Marco, Xiao \& Capanoglu, 2019; Saifullah, et al., 2019). Neste trabalho, serão abordadas as técnicas de encapsulamento mais comumente utilizadas.

\subsection{Métodos físicos}

\subsubsection{Spray drying}

Consiste em um processo de secagem utilizado na indústria de alimentos desde 1950 e bastante usual como técnica de encapsulamento (Souza Simões, et al., 2017), devido ao fato de permitir em uma única operação fazer a formação do material encapsulado e a sua secagem para obtê-lo em pó. É uma técnica amplamente testada para o encapsulamento de bioativos (Shishir \& Chen, 2017), permitindo uma fácil adequação para a produção em escala industrial com mínimos custos operacionais e com processos simples e flexíveis (Geranpour, Assadpour \& Jafari, 2020; Saifullah, et al., 2019).

Para o encapsulamento, inicialmente é feito a dispersão do agente ativo no material de parede, podendo ser mais de um, em uma solução ou suspensão, sendo possível a aplicação de etapas de homogeneizações em alta pressão, microfluidização (Saifullah, et al., 2019), sonicação ou estudos de estabilidade de emulsão. De acordo com Shishir, Taip, Saifullah, Aziz \& Talib, (2017) e Sultana et al. (2017), o material de parede deve ser solúvel em água devido maior compatibilidade com a secagem por pulverização e capaz de formar gel, porém com baixa viscosidade em alta concentração para não ocorrer o entupimento do bico atomizador.

Após a formação da solução, esta é injetada no equipamento através de um bico atomizador, formando pequenas gotículas que entram na câmera de secagem, a qual ocorre um fluxo de ar quente em contracorrente com a alimentação, evaporando o solvente, secando as gotículas e seguindo-se para a recuperação do material em pó no coletor ciclone ou filtro (Ozkan, et al., 2019; Shishir \& Chen, 2017). 
Embora seja uma operação de secagem com aplicação de temperatura alcançando 220 a $250{ }^{\circ} \mathrm{C}$, o núcleo do encapsulado não chega a essa faixa devido à alta velocidade da secagem (Islam, Mahmud, Nawas, Fang \& Xia, 2018). Contudo, materiais com alta sensibilidade podem ter uma perda considerável, mesmo com alguns segundos em contato com a temperatura da câmera de secagem, é o que podemos ver no trabalho de Sultana et al. (2017). Nesse estudo, utilizando a liofilização para encapsular D-limoneno e hexanoato de etila, os autores obtiveram apenas respectivamente, $49 \%$ e $37 \%$ de encapsulamento dos ativos, usando material de parede formado por células mortas de Saccharomyces cerevisiae.

\subsubsection{Liofilização}

A liofilização é uma desidratação com baixas temperaturas, consistindo inicialmente na etapa de congelamento da amostra ou solução, o abaixamento da pressão para remoção da água presente por sublimação, a dessorção, e por último, o armazenamento em local seco para evitar ganho de umidade. Ao utilizar baixas temperaturas e a remoção de oxigênio do processo é possível controlar os efeitos oxidativos sobre os materiais a serem desidratados (Jamshidi, Cao, Xiao \& SimalGandara, 2020; Ozkan, et al., 2019).

É uma técnica adequada quando o agente ativo é bastante sensível a temperaturas elevadas e não pode ser encapsulado através de técnicas como o spray drying. Contudo, existem algumas desvantagens, tais como, o longo período de secagem, mais de 20 h, o alto custo energético, e a formação de porosidade na matriz da partícula que dependendo da aplicação não é desejável, pois favorece a liberação rápida do agente ativo e expô-lo a interferências ambientais externas, mesmo que mínimas, como também a irregularidade do tamanho das partículas, visto que após a finalização da secagem essas precisam ser trituradas ou pulverizadas para obtê-las em pó (Ozkan, et al., 2019).

No trabalho de Li et al. (2019) que encapsularam microrganismos de ação probiótica, que são bastante sensíveis as condições ácidas do sistema digestivo. Nesse estudo, Lactobacillus casei BNCC 134415 foram encapsulados com a técnica de liofilização utilizando a mistura de proteína de soro de leite, goma gelana e ftalato de acetado de celulose como materiais de parede $(10 \%, 0,3 \%$ e $4 \%$ p/v, respectivamente), obtendo no teste simulado de fluídos gastrointestinais a redução de apenas 0,27-0,88 log UFC $\mathrm{mL}^{-1}$, no qual quando colocado amostras no mesmo experimento sem estar encapsulado nenhuma célula livre sobreviveu.

Já em trabalho desenvolvido por Chan, E et al. (2011) com Lactobacillus casei como agente ativo foi proposto o preenchimento com amido a matriz de alginato para melhorar as propriedades físicas das partículas na secagem por liofilização, tais como a redução da matriz porosa. Em seus estudos encontraram que existia uma relação linear entre o aumento da carga de preenchimento com a diminuição dos poros, sendo que o material sem preenchimento teve três vezes mais poros, e no experimento de estabilidade nas condições de $44 \%$ de umidade relativa a $30^{\circ} \mathrm{C}$, o material com amido teve quatro vezes maior estabilidade do que o material encapsulado sem preenchimento.

Nas soluções de carboidratos com maior concentração de soluto quando liofilizados resultaram em um pó com menor grau de porosidade e maior densidade, resultando na menor exposição do agente ativo, visto a menor relação entre a superfície e a massa de material seco (Michalska \& Lech, 2018). Portanto, o uso de materiais de preenchimento podem ser uma alternativa para o controle do aspecto poroso que a liofilização provoca nas partículas.

\subsubsection{Leito fluidizado}

A sua operação se baseia na suspensão de sólidos particulados por uma corrente de um fluido em direção ascendente, ocasionando uma semelhança no movimento do fluído e dos sólidos (Alagha \& Szentannai, 2020). É indicado para a secagem de materiais sensíveis ao calor devido ao uso de temperaturas mais baixas $\left(50\right.$ a $\left.60{ }^{\circ} \mathrm{C}\right)$, apresentando uma boa taxa de 
transferência de calor e massa, além de promover excelente mistura dos materiais que permite a obtenção de particulados homogêneos (Alagha \& Szentannai, 2020; Lehmann, et al., 2019). Bastante utilizada na indústria de alimentos e farmacêutica.

Quando nos referimos a encapsulamento, podemos dizer que o leito fluidizado promove a formação de partículas revestidas por conta da pulverização de um agente encapsulante com a presença de um leito de um pó fluidizado. Conforme Haas et al. (2020), é um processo bastante versátil em virtude de uma maior flexibilidade do design das partículas, com o controle dos parâmetros do processo, como a velocidade de temperatura do ar de entrada e a posição do bico do pulverizador, consequentemente ocorrendo variação do tamanho do particulado, porosidade e a distribuição dos componentes no material seco formado.

Em seu trabalho, Benelli e Oliveira (2019) encapsularam um extrato rico de polifenóis de alecrim (Rosmarinus officinalis L.) por leito fluidizado em sistema lipídico, variando a adição de goma arábica ou soro de leite como material de parede. Contudo, os autores não observaram diferença estatística entre o uso dos materiais de parede, obtendo uma boa resposta no encapsulamento de bioativos com valores superiores a 70\% na retenção dos ácidos rosmarínico, carnósico e carnosol e de 60\% para o ácido caféico. Kim et al. (2019) realizaram um teste sensorial de um doce mastigável incorporado de partículas de hortelã-pimenta obtidas pelas técnicas de spray drying, extrusão e leito fluidizado. Percebendo que os provadores tinham uma maior percepção de sabor do material encapsulado por spray drying, mas levando em conta consumidores que possuem um hábito de processamento oral prolongado, os materiais obtidos por leito fluidizado e extrusão seriam mais indicados, uma vez que permitem uma liberação mais prolongada do flavor.

\subsection{Métodos químicos}

\subsubsection{Complexação de inclusão molecular}

A técnica também pode ser chamada de inclusão molecular de ciclodextrinas (Saifullah, et al., 2019; ZambranoZaragoza \& Quintanar-Guerrero, 2019), visto que as ciclodextrinas são as moléculas utilizadas como material de parede de forma mais usual, pois sua estrutura química é formada por uma porção externa hidrofílica e uma outra interna hidrofóbica. É um processo de encapsulamento indicado para agentes ativos que são apolares, aprisionados na parte interna apolar da matriz por meio de interações de natureza hidrofóbicas (Ozkan, et al., 2019).

Entre os métodos de formação reacional das partículas o mais utilizado é aquele no qual a ciclodextrina é dissolvida em água em concentração que permaneça uma pasta viscosa, seguindo-se a adição do agente ativo enquanto acontece a mistura para que ocorra o complexo de inclusão, não necessitando de etapas posteriores de separação e secagem (Ozkan, et al., 2019).

Em trabalho de Xiao, Hou, Kang, Niu \& Kou (2019), o aroma de melancia foi encapsulado com $\gamma$-ciclodextrina e observaram que dependendo do grupo funcional do composto, o aroma mudava o perfil de retenção, sendo que foi verificado seu aumento de acordo com a classe química: álcoois, aldeídos e ésteres, sugerindo que as estruturas moleculares devem ser levadas em questão, pois afetam o grau de retenção e liberação o ativo

\subsubsection{Polimerização in situ e interfacial}

Entre os métodos de encapsulamento que envolve fenômenos de polimerização temos o interfacial e o in situ. A diferença ocorre se a dispersão dos monômeros que irão formar o polímero de encapsulamento (material de parede) ocorrerá na fase dispersa e/ou contínua. De semelhança temos que ambos os métodos partem de emulsões de água em óleo (A/O) ou óleo em água (O/A) e que ocorre a formação de um polímero através do processo reacional da ligação de monômeros.

A polimerização in situ parte-se de uma emulsão de O/A, em que são dispersos monômeros na fase contínua que ao sofrerem reação de polimerização formam um invólucro ao redor das gotículas de óleo, a fase dispersa, isto é iniciado com o 
uso de substâncias precipitantes, alteração do pH ou mudança de temperatura. A formação do polímero ocorre na região de interface entre as duas fases da emulsão, dependendo dos monômeros utilizados e solventes o material particulado formará um precipitado ou um floculado (Nguon, Lagugné-Labarthet, Brandys, Li \& Gillies, 2018; Zhang, et al., 2020). Esta técnica já vem sendo utilizada em áreas, como indústrias de papel, médica e de formação de PCM, material de mudança de fase, para armazenamento de energia térmica (Han, et al., 2020; Zhang, et al., 2020).

No caso da polimerização interfacial temos monômeros de afinidades diferentes, um hidrofílico e o outro hidrofóbico, a qual cada um estará dissolvido em uma fase diferente, contínua ou dispersa. Para a formação da partícula, os monômeros de ambas as fases irão migrar para a camada interfacial e, neste estágio, iniciar-se a polimerização, por isso o nome da técnica. Como desvantagem pode-se ter a formação de uma matriz encapsulante frágil e a presença de um monômero reativo em contato com o agente ativo pode ser prejudicial (Nguon, et al., 2018).

\subsection{Métodos físico-químicos}

\subsubsection{Coacervação}

A técnica de coacervação é baseada na interação de polímeros polieletrólitos, possuidores de cargas, que ao interagirem formam um revestimento ao redor do agente ativo na solução encapsulante. A técnica é dividida em simples e complexa. Na formação dos coacervados no método simples temos a presença de apenas um polímero e na complexa, a presença de dois ou mais (Eghbal \& Choudhary, 2018; Hernández-Nava, López-Malo, Palou, Ramírez-Corona \& JiménezMunguía, 2020).

Para a formação das partículas, os materiais de parede são homogeneizados em uma solução aquosa em conjunto com o agente ativo de interesse, seguindo-se pela alteração do ponto isoelétrico dos polímeros presentes através de precipitantes, alteração no pH ou mudanças de temperatura. No caso da coacervação complexa, normalmente são usados dois polímeros com cargas opostas, o que permite a interação entre estes e a aproximação ao ponto zero de carga. Com o alcance do ponto isoelétrico atuam formações de interações eletrostáticas nos polímeros, forças de Van der Waals e de interações de caráter hidrofóbicas, formando um revestimento ao redor das gotículas do agente ativo presente na solução. Segue-se então, o repouso da solução que permitirá o enrijecimento da parede depositada e, por final, técnicas de secagem para a obtenção do material em pó, quando necessário (Silva, et al., 2017; Hernández-Nava, et al., 2020; Timilsena, Akanbi, Khalid, Adhikari \& Barrow, 2019).

A técnica é usada principalmente para o encapsulamento de materiais lipídicos (Ferreira \& Nicoletti, 2021; Bastos, Vicente, Santos, Carvalho \& Garcia-Rojas, 2020; Rios-Mera, et al., 2019), formando uma camada de proteção a fatores ambientais e a conversão destes em um produto em pó, que muitas vezes é mais fácil para aplicação industrial. Contudo, o processo de secagem como uma operação a mais na obtenção do material também é um fator de geração de custos.

Em trabalhos como o de Nascimento et al. (2020) onde encapsularam o óleo de pequi em matriz de goma de cajueiro e gelatina, e de Alexandre et al. (2019) utilizando as mesmas condições de formação da partícula, porém usaram o ácido tânico para a reticulação das partículas e o fortalecimento da matriz encapsulante a danos térmicos e mecânicos, foi obtido eficiência de encapsulamento $(71 \%)$ não muito distante do obtido no trabalho de Nascimento $(70 \%)$, tornando uma operação promissora em processos que buscam o enrijecimento da matriz encapsulante da partícula.

\subsubsection{Gelificação iônica}

A técnica de encapsulamento por gelificação iônica é simples e de baixo custo. A formação do material particulado é a partir de uma emulsão, incluindo os polímeros de parede e o agente ativo, a qual é gotejada em uma solução de 
cálcio (iônica) e, imediatamente, formados os particulados esféricos em gel com o agente ativo disperso em sua matriz polimérica (Fernando, Lee, Han \& Ahn, 2020; Kurozawa \& Hubinger, 2017).

A produção de particulados por gelificação iônica é dividida em interna e externa. Na gelificação externa são utilizados agentes ativos hidrofóbicos e na interna, aqueles de comportamento hidrofílico. Existe uma maior dificuldade no encapsulamento de agentes ativos com afinidade a água (hidrofílicas) por esse método, devido a miscibilidade dos hidrocolóides em agentes ativos hidrofílicos, dificultando a separação do núcleo da matriz encapsulante (Kurozawa \& Hubinger, 2017).

O método é baseado na capacidade de reticulação de polímeros (alginato, quitosana, pectina, carboximetilcelulose etc.) que possuem cargas quando expostos aos íons monovalente, divalente ou trivalentes (Ozkan, et al., 2019). O íon reticulante na gelificação interna é encontrado juntamente à solução polimérica na forma inativa enquanto na externa, o íon reticulante é disposto externamente à solução de polímero (Chan, Lee \& Heng, 2006). Contudo, a técnica de gelificação externa apresenta como desvantagem o possível fenômeno de gelificação heterogênea da partícula, cuja a superfície da matriz forma o gel, porém isto não se difunde ao núcleo, tornando-o aquoso (Ozkan, et al., 2019).

No trabalho de $\mathrm{Hu}$ et al. (2018) foram encapsulados os óleos de canela, tomilho e gengibre em nanopartículas de matriz de quitosana pela técnica de gelificação iônica. Os autores encontraram eficiência de encapsulamento de $90 \%$ e, que após 18 dias de armazenamento a $40^{\circ} \mathrm{C}$, ainda ocorreu a retenção de agentes antimicrobianos dos óleos na faixa de $60-70 \%$, indicativo de ótima capacidade de liberação controlada para aplicações de ação antibacteriana de forma prolongada. No trabalho de Menin et al. (2018), partículas de óleo de linhaça encapsuladas por gelificação iônica foram secas em temperatura ambiente $\left(25^{\circ} \mathrm{C}\right)$ e em leito fluidizado. Foi observado que a demora de $48 \mathrm{~h}$ para secagem em temperatura ambiente foi fator proeminente para que ocorresse maior oxidação lipídica, visto que ficaram por maior tempo em contato com água, que é um catalisador de processos oxidativos em óleos.

\subsubsection{Lipossomas}

São vacúolos lipídicos formados por um sistema de bicamada de fosfolipídeos, que possuem uma região caudal hidrofóbica e grupos na região da cabeça hidrofílicos. São estruturas com propriedades biofísicas semelhantes às células, o que permite boas características de biodisponibilidade e permeabilidade a membrana celular para a partícula. Nas aplicações na área de alimentos vem sendo utilizada como método para a retenção de aromas, vitaminas, corantes, enzimas, probióticos, antioxidantes, entre outros (Ozkan, et al., 2019; Trucillo, Campardelli \& Reverchon, 2018).

A técnica se baseia na adição de fosfolipídeos em um solvente orgânico o qual se desagrega em moléculas individuais, seguido da remoção do solvente por diferentes formas (evaporação, dispersão, adição de antissolvente, etc) e a exposição da porção lipídica a ambientes aquosos para permitir a formação de lipossomas, no qual em razão das propriedades anfifílicas irão formar vacúolos retendo em seu interior o agente ativo (Dag, Guner \& Oztop, 2019; Ozkan, et al., 2019).

Apresentam como desvantagens a baixa estabilidade física e química, porém, existem estudos que revestem (coencapsulamento) os lipossomas por uma camada biopolimérica, desta forma, reduzindo efeitos de oxidação lipídica e melhorando a estabilidade (Dag, et al., 2019).

\subsection{Métodos emergentes}

\subsubsection{Eletropulverização}

Apresenta-se como um processo eletro-hidrodinâmico, escaonável a nível industrial e relativamente econômico, conduzido a temperatura ambiente $\left(25^{\circ} \mathrm{C}\right)$, o que é aconselhável na preservação de compostos biológicos sensíveis 
termicamente. E semelhante a eletropulverização temos a eletrofiação. A diferença entre esses processos consiste na concentração de sólidos na solução, pois quando a solução encapsulante é expelida pelo bico capilar, caso tenha baixa concentração de polímeros, ocorre a desestabilização e formação de gotículas carregadas que vão dar origem às partículas (eletropulverização), quando é alta concentração de polímeros a desestabilização não ocorre e são formadas fibras (eletrofiação) (Niu, Shao, Luo \& Sun, 2020).

O princípio de funcionamento inclui uma fonte de alimentação de alta tensão, que irá criar um campo elétrico, um bico capilar onde será expelido a solução polimérica e um coletor. O campo elétrico é formado entre o bico capilar e o coletor, quando ocorre a extrusão da solução esta sofre influência do campo elétrico de forças eletrostáticas mais fortes que a tensão superficial do fluido, sofrendo instabilidade, formando um cone (Cone de Taylor) em um primeiro momento e com a maior tensão aplicada, um jato oscilatório, que no rompimento gera gotículas que seguem até o coletor. Esse percurso é acompanhado da evaporação do solvente e solidificação das gotículas (Nikoo, Kadkhodaee, Ghorani, Razzaq \& Tucker, 2018; Niu, et al., 2020). A principal desvantagem da técnica está no baixo rendimento, porém já existem alternativas como o aumento dos jatos pulverizados em estudo (Niu, et al., 2020).

No uso exploratório da técnica foram encontradas cepas probióticas (Bifidobacterium longum subsp. infantis CECT 4552) liofilizadas e revestidas por processo de eletropulverização com polinivilpirrolidona (PVP) resistindo com contagem de $6 \log$ UFC/mL por até 600 dias em temperatura ambiente a 23\% de umidade, tempo não alcançado no tratamento controle (Librán, et al., 2017). Em estudo de Zaeim, Sarabi-Jamab, Ghorani, Kadkhodaee e Tromp (2017) no processo utilizando via úmida observou-se que a cepa probiótica ( $L b$. plantarum ATCC 8014) teve sobrevivência de $98 \%$ de células viáveis após o encapsulamento. Por sua vez, Rodrigues et al. (2020) exploraram a importância de estudos de interação entre os materiais utilizados, no qual observou-se que o etanol e o $\beta$-caroteno (agente ativo) influenciaram na conformação da proteína utilizada como material de parede e, consequentemente, no processo de agregação e formação do material.

\subsubsection{Revestimento multicamadas}

A técnica de encapsulamento por revestimento multicamadas ou deposição eletrostática consiste em diversas camadas de polieletrólitos (polímeros carregados) encapsulando as gotículas lipídicas em uma emulsão O/A, sendo esta a condição primária, ou seja, apenas com um emulsificante interagindo, muito suscetível a pressões externas, tais como aquecimento, congelamento, alterações de pH, concentração salina (força iônica), secagem entre outros fenômenos que desestabilizem as interações químicas formadas (Griffin \& Khouryieh, 2020). O uso do sistema de multicamadas permite uma maior resistência a essas situações, pois ocorre a deposição de diversas camadas no encapsulamento do agente ativo, e dessa forma, protegendoo mais eficientemente.

A primeira etapa do processo um emulsificante com cargas, por exemplo uma proteína, é adicionado para interagir na interface O/A da emulsão, formando a emulsão primária, em seguida um outro polímero, como um carboidrato, também carregado, porém de carga oposta ao primeiro é adicionado, por atração de cargas opostas este também se adsorve ao redor da gotícula lipídica. Na etapa posterior, um novo polieletrólito de carga contrária à da emulsão secundária irá também ser depositado ao redor da partícula, dando origem a emulsão terciária (Burgos-Díaz, et al., 2018; Fang, Zhao, Liu, Liang \& Yang, 2019). Por este sistema de adições de biopolímeros carregados interagindo de forma não covalente são formadas as sucessivas camadas de revestimento. Normalmente são encontradas até três camadas de formação.

É importante abordar que a técnica permite uma modelagem funcional mais flexível da partícula, pois o número de camadas ou a ordem dos polieletrólitos (negativo e positivo) a serem depositados vai influenciar na espessura final, permeabilidade e carga, sendo sempre reflexo da carga líquida da última camada. Dessa forma, manipulando mais 
eficientemente, por exemplo, a carga final do material em função daquela mais ideal pode ser interessante para a possível aplicação ou a melhor resistência em processos de secagem como o spray drying ( Liu, Tan, Xu, McCleiments \& Wang, 2019; Muriel Mundo, Zhou, Tan, Liu \& McClements, 2020).

Em trabalho de Chen et al. (2020) utilizaram a técnica de revestimento multicamadas para superar a dificuldade no encapsulamento de dois nutracêuticos (coenzima Q10 e piperina) de polaridades diferentes para ter ação fisiológica sinergética. No estudo, a coenzima Q10 foi incorporada ao núcleo revestido pela zeína (carga positiva), seguida da pectina (carga negativa) e a piperina foi incorporada entre essa camada de pectina e a terceira e última das multicamadas (quitosana) de carga positiva.

\section{Agentes ativos de interesse para o setor alimentício}

Entre as diversas macromoléculas que é despertado o interesse de serem encapsuladas aquelas mais utilizadas nas indústrias de alimentos são os bioativos, corantes, aromatizantes, óleos, probióticos e enzimas. Os processos que permitem a melhor conservação e, consequentemente, a redução de efeitos deletérios são promissores no incentivo de aplicação industrial. Este tópico, portanto, irá apresentar e explicar brevemente sobre essas macromoléculas e seus benefícios. No tópico posterior se encontra uma tabela com trabalhos abordando os agentes ativos que são citados nessa seção.

\subsection{Bioativos}

Os compostos bioativos são encontrados em alimentos, majoritariamente aqueles de origem vegetal, tais como em cereais, frutas, raízes e leguminosas, que não possuem a função primordial como os demais nutrientes de suprir energeticamente e estruturalmente os organismos vivos, mas que atuam em sistemas auxiliares na prevenção de doenças (Shishir, Xie, Sun, Zheng \& Chen, 2018). É um grupo bastante amplo, a qual alguns deles serão abordados individualmente em alguns tópicos como agentes ativos, visto a sua importância e pesquisas com seu uso. Sendo representados pelos alcalóides, carotenóides, fenólicos, probióticos, vitaminas lipossolúveis, organossulfurados, entre outros (Niu, et al., 2020).

Os bioativos podem atuar na prevenção de câncer, diabetes, processos inflamatórios, doenças cardiovasculares, obesidade, úlceras estomacais, etc. (Shishir, et al., 2018; Zhang, et al., 2020). Contudo, são macromoléculas instáveis e facilmente suscetíveis à oxidação quando entram em contato com oxigênio, luz e calor durante o preparo do alimento e armazenamento, perdendo o efeito de benefício a saúde, além dos flavors desagradáveis, como os apresentados pelas saponinas (Wen, et al., 2017). Outro fator limitante é a baixa biodisponibilidade que pode ser causada tanto pela sensibilidade aos processos oxidativos, hidrofobicidade e perda da atividade biológica nos casos de moléculas biológicas, contribuindo para a dificuldade de consumo (Zhang, et al., 2020). Os métodos de encapsulamento apresentam-se como alternativa para melhores respostas no que concerne à maior estabilidade oxidativa e entrega direcionada.

Duas escolhas são importantes no encapsulamento de bioativos: a seleção de materiais de parede geralmente conhecidos como seguros (GRAS) e a técnica adequada para a sua retenção (Shishir, et al., 2018), pois algumas delas podem levar o uso de reagentes, operações ou temperatura que danifique a estrutura da molécula, promovendo a perda de sua funcionalidade.

\subsection{Corantes e Aromatizantes}

Devido às condições de processamento ou até mesmo no decorrer do tempo de armazenamento, os alimentos costumam perder algumas características sensoriais que os definem. Dessa forma, as indústrias utilizam aromas e corantes para oferecer ao alimento um aspecto esperado pelos consumidores. Uma vez que, a cor e o aroma são de suma importância ao que se refere a incentivar a sua comercialização (Xiao, et al., 2019). 
Nos dias atuais, com o avanço das pesquisas sobre os aditivos sintéticos, houve a identificação de toxicidade e danos à saúde, como a ação cancerígena (Martins, Roriz, Morales, Barros \& Ferreira, 2016), isto associado ao aumento de consumidores mais exigentes com os alimentos. Assim, fizeram com que o uso de aditivos oriundos de síntese química fosse repensado, e houve o estímulo do uso de aditivos de origem natural. Entretanto, estes necessitam da aplicação de tecnologias de conservação para contornar a sensibilidade que apresentam à degradação, sendo o encapsulamento uma das formas assistidas para a problemática (Martins, et al., 2016; Zhou, et al., 2017).

Tanto os aromas quanto os sabores são geralmente moléculas de baixo peso molecular, o que os tornam sensíveis ao ar, calor, umidade e luminosidade. Quando adicionamos estes aditivos em alimentos processados de forma livre ocorrem perdas durante as etapas de processamento e armazenamento, por isto que as técnicas de encapsulamento são indicadas para pré-encapsular esses compostos antes do uso em alimentos e bebidas (Saifullah, et al., 2019; Xiao, et al., 2019). Ao revestir o material com um biopolímero também revertemos problemas associados à baixa solubilidade em água (Petito, Dias, Costa, Falcão \& Araujo, 2016). Tornando o encapsulamento uma tecnologia para conservação de aromas e corantes, proporcionando o aumento da estabilidade e tempo de prateleira.

\section{3 Óleos}

O consumo de óleos vegetais é incentivado e até vem sendo incorporado nos alimentos durante os últimos anos como tática de adicionar características funcionais ao produto (Delshadi, Bahrami, Tafti, Barba \& Williams, 2020). Através de alguns óleos conseguimos o consumo de ácidos graxos essenciais, o ácido linolênico ( $\omega$-3) e o ácido linoleico ( $\omega$-6), quando ocorre a falta destes no organismo pode causar danos à saúde, como doenças inflamatórias no trato gastrointestinal, surgimento de fístulas no intestino delgado, problemas no pâncreas, entre outras enfermidades (Mogensen, 2017), além de agirem como precursores de outros ácidos graxos com importantes funções, como o ácido linoleico que dá origem ao ácido araquidônico, importante para as funções celulares, musculares e para os sistemas imunológico e nervoso (Tallima \& El Ridi, 2018). Existem também outros benefícios que podem ser encontrados na constituição de alguns óleos e que promovem respostas antiinflamatória, anticâncer, antioxidante e antiviral ( Ruiz, Vazquez \& Campos, 2017).

Dentro do grupo de óleos vegetais, normalmente extraídos de sementes, temos os óleos essenciais que resultam de processos metabólitos secundários, que por sua vez, são extraídos de outras partes da planta, como as flores, e apresentam alta sensibilidade aos efeitos oxidativos (Delshadi, et al., 2020; Giacometti, et al., 2018), mas ganham destaque devido, por exemplo, a ação antimicrobiana dos terpenóides, ácidos fenólicos (Bastos, et al., 2020), timol, carvacrol (Radünz, et al., 2020), entre outras substâncias, que estão presentes em alguns óleos essenciais e possuem atividade na destruição da membrana de bactérias através da desestabilização da camada lipídica ou como inseticida natural, tais como o mentol presente no óleo essencial da hortelã-pimenta (Mentha X piperita) (Rajkumar, Gunasekaran, Paul \& Dharmaraj, 2020).

Os efeitos oxidativos que atuam nos óleos são causados por reações enzimáticas e não enzimáticas, esta podendo ainda ser atribuída a processos de auto oxidação ou foto-oxidação e são desencadeados desde a extração, prosseguindo durante o processamento e armazenamento. São acelerados quando expostos a oxigênio, umidade, metais, ácidos graxos livres, entre outros, levando a formação de compostos que atribui o aspecto rançoso e sabores desagradáveis, a saber, aldeídos, cetonas, ésteres, hidrocarbonetos e álcoois (Sharma, et al., 2019). O que reflete no uso do encapsulamento como alternativa para proteção de óleos e minimização dos processos degenerativos resultantes de fatores ambientais. 


\subsection{Probióticos}

De acordo com a Food and Agriculture Organization of the United Nations e a World Health Organization [FAO/WHO] (2001) os probióticos são microrganismos que quando administrados em quantidades adequadas são capazes de proporcionar benefícios ao indivíduo, embora exista uma indicação de consumo de $10^{6}$ a $10^{8}$ de células viáveis (Kim, Keogh \& Clifton, 2018), esta quantidade é dependente da cepa probiótica e do alimento o qual está sendo realizado a veiculação.

Entre os benefícios do consumo está a regulação de problemas gastrointestinais, tratamento e controle de doenças cardiovasculares, hepáticas e neurológicas, efeitos antitumorais, ação restauradora da microbiota intestinal, redução de efeitos provocados pela má digestão da lactose, entre outros (Dhillon, Singh \& Kaur, 2020; Li, et al., 2020; Quigley, 2019), porém isto apenas é manifestado quando ocorre um contínuo consumo.

O uso e estudo de probióticos deve considerar as especificidades da população, caso contrário poderá causar problemas no tratamento de alguma enfermidade ou até mesmo consequências à saúde dos indivíduos (Besselink, et al., 2008). Alguns estudos apontam os malefícios do consumo de probióticos, tais como, a transferência de genes com resistência a alguns antibióticos, endocardite e condições imunocomprometidas, como a bacteremia (Li, et al., 2020).

Todavia, as pesquisas são ainda inconclusivas a respeito dos benefícios ou malefícios e isto também é variável da cepa probiótica, portanto, o consumo ainda é incentivado e para permitir que os microrganismos de ação probiótica estejam vivos e que suportem os processamentos na formulação do alimento, armazenamento e as condições ácidas do trato gastrointestinal (Kim, et al., 2009), a tecnologia de encapsulamento é uma tática promissora.

\subsection{Enzimas}

Enzimas são moléculas orgânicas formadas a partir de estruturas de aminoácidos e em alguns casos necessitam de substâncias não proteicas, cofatores e coenzimas, para a sua ação biológica. São catalisadores bastante eficientes e seletivos para os diversos processos em organismos vivos (Valldeperas, et al., 2019), são encontradas internamente e externamente em células e como metabólitos formados na atividade microbiana (Malar, Seenuvasan, Kumar, Kumar \& Parthiban, 2020).

O uso industrial é bastante crescente englobando indústrias de biocombustíveis, detergentes, papel, energia, farmacêutica, cosmética e a de alimentos, por exemplo, na produção de cerveja e laticínios. A demanda vem aumentando e projeta-se para o ano de 2020 que as enzimas irão contribuir em 7,2 bilhões de dólares no mercado global, justificado pela cobrança de processos no segmento da biotecnologia industrial, respeito ao meio ambiente, a alta especificidade e o incentivo que os processos de otimização na engenharia de proteínas proporcionam na amplitude de aplicações (Wilkerson, Yang, Funk, Stanley \& Bundy, 2018).

Ao projetar o uso enzimático nos deparamos com o problema de que sua estabilidade é dependente das interações formadas em sua estrutura, a qual podem ser facilmente desestabilizadas ao mudar o ambiente em condições biologicamente adversas, tais como mudanças de temperatura, $\mathrm{pH}$ ou forças iônicas, podendo perder a sua capacidade catalítica. $\mathrm{O}$ que torna o encapsulamento uma alternativa para aumentar a estabilidade enzimática e operacional, além de proporcionar a redução dos custos envolvidos (Long, Pan, Xie, Xu \& Jin, 2020), pois a matriz de revestimento atuaria como uma defesa frente às condições de pH, temperatura e concentrações salinas que as enzimas não suportariam no estado livre (Valldeperas, et al., 2019).

\section{Aplicações no Setor Alimentício e Perspectivas Futuras}

A partir do que foi explanado sobre a tecnologia de encapsulamento, incluindo definição, caracterização, algumas das técnicas utilizadas e as principais classes de compostos ativos que são explorados no encapsulamento para o setor alimentício, 
agora será iniciada a discussão de como estão ocorrendo as aplicações dos produtos particulados, assim como abordaremos quais foram as respostas positivas e negativas encontradas através da sua utilização e o que ainda está aberto como possibilidades de melhorias nas perspectivas futuras de pesquisas nesse segmento.

Este tópico se encontra dividido em estudos de aplicação dos particulados diretamente na matriz alimentícia, como um ingrediente, e em estudos do seu uso dentro dos processos industriais.

\subsection{Aplicações em matriz alimentícia}

Ao utilizar materiais encapsulados diretamente na matriz alimentícia, como parte da sua formulação, podemos obter o enriquecimento do produto, por exemplo, atribuir atividade antioxidante (Yan, et al., 2018), ter ação tecnológica, por exemplo, quando temos a liberação controlada de um corante, o que permite maior manutenção da cor, ou ainda ação de um antimicrobiano e até mesmo como realizado por Haghighat-Kharazi, Jafar, Kasaai e Khajeh, (2019), que encapsularam amilase maltogênica para uso em pães sem glúten permitindo a maior retenção de umidade e aumento e uniformidade dos alvéolos.

Na Tabela 1 podemos observar alguns trabalhos que estudaram aplicações de particulados em diversos alimentos, e se isto atendeu ou não as expectativas esperadas, pois algumas vezes o material projetado em bancada de laboratório não mantém estabilidade dentro de uma formulação alimentícia complexa, estando sujeito a diversas etapas de preparo que podem ser significativas para a degradação em situações não programadas.

No trabalho de Moura et al. (2019), por exemplo, o extrato de hibisco encapsulado não teve boa retenção na bala de pectina e também promoveu um aspecto não favorável a aceitação sensorial do doce e a não homogeneidade do produto, no qual foi possível observar as estruturas esféricas dos particulados no doce. 
Research, Society and Development, v. 10, n. 7, e6210716240, 2021

(CC BY 4.0) | ISSN 2525-3409 | DOI: http://dx.doi.org/10.33448/rsd-v10i7.16240

Tabela 1. Materiais encapsulados encontrados em alimentos.

\begin{tabular}{|c|c|c|c|c|c|}
\hline Alimento & Agente ativo & $\begin{array}{l}\text { Material de } \\
\text { Parede }\end{array}$ & $\begin{array}{c}\text { Método de } \\
\text { encapsulamento }\end{array}$ & Resultados & Referência \\
\hline $\begin{array}{l}\text { Balas de geleia } \\
\quad \text { (pectina) }\end{array}$ & $\begin{array}{l}\text { Extrato de hibisco } \\
\quad \text { (Hibiscus } \\
\text { sabdariffa L.) }\end{array}$ & Pectina & $\begin{array}{c}\text { Gelificação iônica e } \\
\text { spray drying }\end{array}$ & $\begin{array}{l}\text {-As balas tiveram maior retenção dos bioativos do extrato quando } \\
\text { aplicado livre do que particulado; } \\
\text {-As balas com partículas não tiveram homogeneização da cor, } \\
\text { porém, maior manutenção desta ao tempo; } \\
\text {-No teste sensorial os provadores preferiram a bala com o extrato } \\
\text { livre do que as balas com o material encapsulado. }\end{array}$ & Moura et al. (2019) \\
\hline $\begin{array}{l}\text { Iogurte natural } \\
\text { turco }\end{array}$ & $\begin{array}{l}\text { Antocianinas de } \\
\text { cenoura preta }(D . \\
\quad \text { carota } \mathrm{L} \text {. } \\
\text { ssp. Sativus var. Atr } \\
\quad \text { orubens Alef. })\end{array}$ & $\begin{array}{c}\text { Proteínas do soro } \\
\text { de leite }\end{array}$ & $\begin{array}{l}\text { Gelificação a } \\
\text { quente }\end{array}$ & $\begin{array}{l}\text {-As cápsulas permitiram uma boa homogeneização de cor no } \\
\text { produto lácteo; } \\
\text {-Maior estabilidade das antocianinas. }\end{array}$ & $\begin{array}{c}\text { Bilek, Yilmaz e Özkan } \\
\text { (2017) }\end{array}$ \\
\hline $\begin{array}{l}\text { Suco de } \\
\text { tamarindo } \\
\text { (Tamarindus } \\
\text { indica } \text { L.) }\end{array}$ & $\begin{array}{l}\text { Óleo de café verde } \\
\text { (Coffea arabica L.) }\end{array}$ & $\begin{array}{l}\text { Goma de cajueiro } \\
\text { e Gelatina }\end{array}$ & $\begin{array}{l}\text { Coacervação } \\
\text { complexa }\end{array}$ & $\begin{array}{l}\text {-Manutenção da morfologia das partículas após aplicação na } \\
\text { bebida; } \\
\text {-As partículas não interferiram na reologia do suco; } \\
\text {-As partículas se encontraram dispersas no suco; } \\
\text {-Não foi detectado liberação do agente ativo em } 30 \text { dias de } \\
\text { armazenamento }\left(5^{\circ} \mathrm{C}\right) \text {. }\end{array}$ & Oliveira et al. (2020) \\
\hline $\begin{array}{l}\text { Iogurte com } \\
\text { sabor de } \\
\text { morango }\end{array}$ & $\begin{array}{l}\text { Óleo de echium ( } E \text {. } \\
\text { plantagineum } \mathrm{L} .) \mathrm{e} \\
\quad \text { fitoesteróis }\end{array}$ & $\begin{array}{l}\text { Gelatina e Goma } \\
\text { de cajueiro; } \\
\text { Gelatina e Goma } \\
\quad \text { arábica }\end{array}$ & $\begin{array}{l}\text { Coacervação } \\
\text { complexa }\end{array}$ & $\begin{array}{l}\text {-As partículas encontraram-se dispersas na matriz alimentícia; } \\
\text {-As partículas alteraram a cor do iogurte durante o armazenamento, } \\
\text { mas não interferiram na aceitação sensorial; } \\
\text {-A aceitação sensorial do iogurte com partículas foi semelhante ao } \\
\text { tratamento controle sem partículas, e maior em relação ao } \\
\text { tratamento com aplicação dos bioativos sem encapsulamento, visto } \\
\text { que não houve o mascaramento do flavor. }\end{array}$ & Comunian et al. (2017) \\
\hline Biscoito & $\begin{array}{l}\text { Extrato de chá } \\
\text { verde }\end{array}$ & Gelatina e Zeina & Eletropulverização & $\begin{array}{l}\text {-O encapsulamento não foi capaz de proteger o agente ativo } \\
\text { durante o preparo do biscoito; } \\
\text {-Não foi observado diferença sensorial entre os biscoitos controle e } \\
\text { o adicionado de micropartículas. }\end{array}$ & $\begin{array}{c}\text { Gómez-Mascaraque et } \\
\text { al. (2017) }\end{array}$ \\
\hline
\end{tabular}


Research, Society and Development, v. 10, n. 7, e6210716240, 2021

(CC BY 4.0) | ISSN 2525-3409 | DOI: http://dx.doi.org/10.33448/rsd-v10i7.16240

\begin{tabular}{|c|c|c|c|c|c|}
\hline $\begin{array}{l}\text { Licor, vinagre } \\
\text { de maçã e } \\
\text { vinagre de arroz }\end{array}$ & Astaxantina & $\begin{array}{c}\text { Zeina e } \\
\text { Oligocitosana }\end{array}$ & Separação de fases & $\begin{array}{l}\text {-Houve dispersão das partículas nas matrizes alimentícias; } \\
\text {-Aumento do perfil antioxidante dos alimentos incorporados de } \\
\text { partículas. }\end{array}$ & Jiang e Zhu (2019) \\
\hline Uísque & Quercetina & $\begin{array}{l}\text { Cloridato de } \\
\text { quitosana e } \\
\text { Carboximetilquito } \\
\quad \text { sana }\end{array}$ & Gelificação iônica & $\begin{array}{l}\text {-Houve aumento da estabilidade química, solubilidade e aumento } \\
\text { da atividade antioxidante da quercetina. }\end{array}$ & Yan et al. (2018) \\
\hline Chá verde & $\begin{array}{l}\text { Lactobacillus } \\
\text { rhamnosus } G G\end{array}$ & $\begin{array}{l}\text { Proteína de soro } \\
\text { de leite e Amido } \\
\text { de huauzontle } \\
\text { modificado }\end{array}$ & Spray drying & $\begin{array}{l}\text {-Após } 5 \text { semanas de armazenamento }\left(4^{\circ} \mathrm{C}\right) \text { foram mantidas } \\
\text { contagens superiores a } 7 \log \mathrm{UFC} / \mathrm{mL} \text {; } \\
\text {-Não houve fermentação da bebida; } \\
\text {-O prazo de validade estabelecido foi de } 23 \text { dias com } 50 \% \text { de } \\
\text { rejeição do consumidor. }\end{array}$ & $\begin{array}{l}\text { Hernández-Barrueta et } \\
\text { al. (2020) }\end{array}$ \\
\hline Iogurte e pão & $\begin{array}{l}\text { Óleo de palma } \\
\text { (Elaeis guineensis) }\end{array}$ & $\begin{array}{l}\text { Quitosana e Goma } \\
\text { xantana; } \\
\text { Quitosana e } \\
\text { Pectina }\end{array}$ & $\begin{array}{l}\text { Coacervação } \\
\text { complexa }\end{array}$ & $\begin{array}{l}\text {-As partículas em matriz de quitosana e pectina foi melhor na } \\
\text { proteção e liberação do agente ativo; } \\
\text {-As partículas na matriz alimentícia no teste em condições } \\
\text { gastrointestinais simuladas obtiveram menor degradação do que o } \\
\text { agente ativo livre; } \\
\text {-O uso em iogurte teve maior liberação do agente ativo. }\end{array}$ & Rutz et al. (2017) \\
\hline $\begin{array}{c}\text { Arroz } \\
\text { instantâneo }\end{array}$ & $\begin{array}{l}\text { 2-acetil-1-pirrolina } \\
\quad \text { (aroma) }\end{array}$ & $\begin{array}{c}\text { Parafina } \\
\text { octacosano }\end{array}$ & Spray chilling & -Ocorreu liberação completa do aroma no preparo do arroz. & $\begin{array}{l}\text { Yin e Cadwallader } \\
\qquad(2019)\end{array}$ \\
\hline
\end{tabular}

Fonte: Autores. 
De forma geral, a aplicação dos particulados em alimentos sólidos ou viscosos é favorecida, pois permitem uma fácil dispersão no produto, como pode ser observado nos muitos testes realizados em iogurte (Comunian, et al., 2017; Bilek, et al., 2017; Gomez-Estaca, Comunian, Montero, Ferro-Furtado \& Favaro-Trindade, 2016; Rutz, et al., 2017). Entretanto, pesquisas como a de Oliveira et al. (2020) já encontram boa dispersão de partículas em produto de maior fluidez (suco de tamarindo), proporcionando importância de mais estudos do uso de materiais particulados em uma gama maior de alimentos, analisando o comportamento das partículas em sua matriz e visualizando, porventura, novos desafios a serem identificados.

A dificuldade em escalonar a produção de partículas em escala industrial é trazer os métodos de formação do encapsulamento a uma produção maior. Como afirmam Waterhouse e Sun-Waterhouse (2019), os métodos de extrusão e spray drying são $80 \%$ dos casos de sucesso nesse desafio, pois são processos de fácil adaptação numa linha industrial.

Ao tomar como exemplo a comparação entre a coacervação complexa e a gelificação iônica, podemos sugerir a última como mais adequada no escalonamento industrial, uma vez que a coacervação complexa já possui em suas etapas de encapsulamento a necessidade de um maior tempo de formação já sistemático, pois precisa de um longo tempo de descanso para que ocorra o enrijecimento da matriz encapsulante. A gelificação iônica, por sua vez, proporciona o enrijecimento mais rápido das partículas e apresenta alternativas industriais de monitorar a quantidade e velocidade de gotejamento da emulsão na solução iônica para maior produção dos particulados.

Pensando nisto, Tang, Scher e Jeoh (2020) sugerem em seu trabalho a condução da etapa de formação de partículas por coacervação complexa e secagem em uma única etapa, reduzindo, assim, o tempo de preparo. Quando os materiais de parede (gelatina e alginato de sódio) são pulverizados juntamente com o agente ativo, dentro da câmara de secagem ocorre a evaporação do solvente fazendo com que aconteça a redução do $\mathrm{pH}$ ao ponto isoelétrico dos materiais de parede, formando os coacervados, a qual no contínuo processo de evaporação do solvente já faz a secagem do material recém-complexado.

No que concerne os desafios devemos pontuar que nem sempre a formação excelente de materiais encapsulados em nível laboratorial terá o mesmo resultado na escala industrial, como ressaltam Waterhouse e Sun-Waterhouse (2019) nos aspectos que devem ser observados:

a) intensificação de interações e dinâmica molecular;

b) efeitos de geometria e confinamento de espaço;

c) tornar efeitos de $\mathrm{pH}$, temperatura, pressão, entre outros em nível homogêneo;

d) presença de sais indefinidos (Ex. fonte de água);

e) interações eletrostáticas não esperadas que podem ocorrer em grandes volumes de material;

f) aglomeração molecular;

g) distribuição de carga;

h) alta tensão de cisalhamento que ocorrem em processos industriais;

i) déficit de tecnologias que acompanhem as mudanças composicionais e de estrutura dos materiais no ciclo industrial.

Sendo importante também a correta condução das boas práticas de produção em respeito às legislações, já que ocorrerá a veiculação em alimentos e no uso de matérias-primas seguras para o consumo que não causem nenhum dano aos consumidores.

\subsection{Aplicações em processos industriais}

A tecnologia de encapsulamento dentro de processos industriais permite o uso de substâncias encapsuladas como parte integrante dos processos que irão dar origem a um produto ou demais processos de interesse na dinâmica industrial, como 
Research, Society and Development, v. 10, n. 7, e6210716240, 2021

(CC BY 4.0) | ISSN 2525-3409 | DOI: http://dx.doi.org/10.33448/rsd-v10i7.16240

no tratamento de resíduos ou no armazenamento de produtos de forma mais eficiente. Entre os agentes ativos que ganham mais destaque neste tipo de aplicação estão as enzimas, os microrganismos e os materiais de mudança de fase (PCM). Na Tabela 2 são apresentados alguns exemplos.

As enzimas como biocatalisadores imobilizados permitem a reutilização em mais ciclos, minimizando problemas relacionados a recuperação das enzimas após as reações. Situação semelhante se aplica ao uso de microrganismos em fermentações. É o que podemos ver no trabalho de Long et al. (2020) que ao encapsularem a $\beta$-frutofuranosidase e a glicose oxidase obtiveram maior estabilidade térmica e reciclagem em oito ciclos ou no trabalho de Kamanina et al. (2016) que propuseram o uso da Ogataea polymorpha VKM Y-2559 na remoção de metanol de resíduos industriais, a qual também está presente na produção de cachaça, por exemplo, tendo resultado três vezes mais eficiente do que o uso de tanques de aeração, comuns industrialmente. 
Research, Society and Development, v. 10, n. 7, e6210716240, 2021

(CC BY 4.0) | ISSN 2525-3409 | DOI: http://dx.doi.org/10.33448/rsd-v10i7.16240

Tabela 2. Tecnologia de encapsulamento no setor alimentício industrial.

\begin{tabular}{|c|c|c|c|c|c|}
\hline Finalidade & Agente ativo & $\begin{array}{l}\text { Material de } \\
\text { Parede }\end{array}$ & $\begin{array}{c}\text { Método de } \\
\text { encapsulamento }\end{array}$ & Resultados & Referência \\
\hline $\begin{array}{c}\text { Produção de um } \\
\text { prebiótico - lactosucrose } \\
\text { (O- } \beta \text { - d -galactopiranosil- } \\
(1,4) \text {-O- } \alpha \text { - d- } \\
\text { glucopiranosil- }(1,2)-\beta \text { - } \\
\text { d - frutofuranosídeo) }\end{array}$ & $\begin{array}{l}\beta- \\
\text { frutofuranosidase } \\
\text { e a Glicose } \\
\text { oxidase }\end{array}$ & $\begin{array}{l}\text { Álcool polivinílico } \\
\text { aquoso }\end{array}$ & Sol-gel & $\begin{array}{l}\text {-O encapsulamento melhorou a estabilidade térmica, } \\
\text { suportando a temperatura de } 40^{\circ} \mathrm{C} \text { e resistência a maiores } \\
\text { faixas de } \mathrm{pH}(<6,5) \text {; } \\
\text {-Obteve uma capacidade operacional de oito ciclos com } \\
82 \% \text { de atividade enzimática; } \\
\text {-Maior produção de lactosucrose nas enzimas encapsuladas } \\
\text { do que livres. }\end{array}$ & Long et al. (2020) \\
\hline $\begin{array}{c}\text { Biofiltros para a remoção } \\
\text { de metanol de águas } \\
\text { residuais industriais }\end{array}$ & $\begin{array}{c}\text { Ogataea } \\
\text { polymorpha } \\
\text { VKM Y-2559 }\end{array}$ & $\begin{array}{l}\text { Sílica modificada } \\
\text { com alquil }\end{array}$ & Sol-gel & $\begin{array}{l}\text {-O biofiltro obteve ação oxidante três vezes mais do que o } \\
\text { uso de tanques de aeração. }\end{array}$ & $\begin{array}{l}\text { Kamanina et al. } \\
\text { (2016) }\end{array}$ \\
\hline $\begin{array}{l}\text { PCM para manutenção de } \\
\text { temperatura em } \\
\text { embalagens para } \\
\text { alimentos }\end{array}$ & $\begin{array}{l}\text { Cera de parafina } \\
\text { de Rubitherm RT5 }\end{array}$ & Poliestireno & Eletrofiação & $\begin{array}{l}\text {-As fibras formadas foram capazes de armazenar } 34 \% \text { de } \\
\text { calor em peso do agente ativo; } \\
\text {-Foi necessário maior tempo para vencer a mudança de } \\
\text { temperatura, mantendo por maior tempo produtos } \\
\text { alimentícios resfriados. }\end{array}$ & $\begin{array}{l}\text { Chalco-Sandoval et } \\
\text { al. (2017) }\end{array}$ \\
\hline $\begin{array}{l}\text { PCM para manutenção de } \\
\text { temperatura em } \\
\text { embalagens para } \\
\text { alimentos }\end{array}$ & Ceras de parafina & $\begin{array}{l}\text { Policaprolactona, } \\
\text { Poliestireno e } \\
\text { Poliestireno de alto } \\
\quad \text { impacto }\end{array}$ & Eletrofiação & $\begin{array}{l}\text {-Grau de super-resfriamento obtido foi semelhante a } \\
\text { parafina pura. }\end{array}$ & $\begin{array}{l}\text { Chalco-Sandoval, } \\
\text { Fabra, López-Rubio } \\
\text { e Lagaron (2015) }\end{array}$ \\
\hline $\begin{array}{l}\text { Hidrólise de lactose do } \\
\quad \text { soro de leite }\end{array}$ & $\begin{array}{l}\beta \text {-galactosidase de } \\
\text { K. lactis }\end{array}$ & $\begin{array}{l}\text { Alginato de cálcio } \\
\text { e Gelatina }\end{array}$ & Gelificação iônica & $\begin{array}{l}\text {-A enzima se mostrou eficaz na redução de } 72 \% \text { de lactose } \\
\text { encontrada no soro de leite; } \\
\text {-A complexação da enzima com concanavalina A permitiu } \\
\text { aumento da taxa de conversão da lactose e diminuindo a } \\
\text { lixiviação da enzima após a hidrólise. }\end{array}$ & $\begin{array}{l}\text { Mörschbächer et al. } \\
\text { (2016) }\end{array}$ \\
\hline $\begin{array}{c}\text { Enzimas encapsuladas } \\
\text { para acelerar a maturação } \\
\text { de queijos }\end{array}$ & $\begin{array}{c}\text { Proteases } \\
\text { (Flavourzyme) }\end{array}$ & $\begin{array}{l}\text { Gelano; k- } \\
\text { carragenina; } \\
\text { Gordura de alto } \\
\text { ponto de fusão da }\end{array}$ & $\begin{array}{l}\text { Dispersão em } \\
\text { duas fases }\end{array}$ & $\begin{array}{l}\text {-Todos os queijos com enzimas encapsuladas tiveram } \\
\text { maior taxa de proteólise, sendo maior no de matriz de K- } \\
\text { carragenina; } \\
\text {-Embora houvesse maior taxa proteolítica não foi }\end{array}$ & $\begin{array}{l}\text { Kailasapathy e Lam } \\
\text { (2005) }\end{array}$ \\
\hline
\end{tabular}


Research, Society and Development, v. 10, n. 7, e6210716240, 2021

(CC BY 4.0) | ISSN 2525-3409 | DOI: http://dx.doi.org/10.33448/rsd-v10i7.16240

\begin{tabular}{|c|c|c|c|c|c|}
\hline & & gordura do leite & & perceptível melhorias na textura do queijo como esperado. & \\
\hline $\begin{array}{l}\text { Cultura iniciais funcionais } \\
\text { para a indústria de } \\
\text { fermentação de alimentos }\end{array}$ & $\begin{array}{l}\text { Lactobacillus } \\
\text { plantarum LUHS1 } \\
\quad 35 \\
\text { e paracasei LUHS } \\
244\end{array}$ & Soro de leite & Spray drying & $\begin{array}{l}\text {-O soro de leite teve tanto a função de material de parede } \\
\text { como substrato para o crescimento dos microrganismos; } \\
\text {-O encapsulamento promoveu maior estabilidade aos } \\
\text { probióticos. }\end{array}$ & $\begin{array}{l}\text { Bartkiene et al. } \\
\qquad(2018)\end{array}$ \\
\hline $\begin{array}{c}\text { Sacarificação de pasta de } \\
\text { mandioca para produção } \\
\text { de glicose }\end{array}$ & $\begin{array}{l}\text { Multienzimas } \\
\text { (alfa-amilase, } \\
\text { glucoamilase e } \\
\text { celulase) }\end{array}$ & $\begin{array}{l}\text { Alginato de cálcio; } \\
\text { Alginato de cálcio } \\
\text { e Argila caulinita }\end{array}$ & Gelificação iônica & $\begin{array}{l}\text {-Foi possível a reutilização da enzima em cinco ciclos com } \\
\text { a preservação de } 51,77 \% \text { da atividade enzimática; } \\
\text {-As partículas em matriz encapsulante de alginato de cálcio } \\
\text { e argila tiveram melhor preservação da atividade } \\
\text { enzimática. }\end{array}$ & Rahim et al. (2013) \\
\hline $\begin{array}{l}\text { Otkailaimização do } \\
\text { processo de conversão da } \\
\text { glicose em frutose }\end{array}$ & $\begin{array}{l}\text { Glicose isomerase } \\
\text { de Streptomyces } \\
\text { enissocaesilis } \\
\text { MN911386 }\end{array}$ & $\begin{array}{c}\text { Quitosana; } \\
\text { Alginato de cálcio; } \\
\text { Ágar }\end{array}$ & Gelificação iônica & $\begin{array}{l}\text {-O encapsulamento em matriz de quitosana, ágar e alginato } \\
\text { de sódio permitiu, respectivamente, o aumento de } 47,18 \% \text {, } \\
19,7 \% \text { e } 18,5 \% \text { da atividade enzimática; } \\
\text {-O encapsulamento em matriz de quitosana foi o que } \\
\text { obteve maior resistência térmica das partículas; } \\
\text {-Quando encapsulado em quitosana aconteceu o aumento } \\
\text { da atividade enzimática em pH ácido, enquanto em ágar o } \\
\text { aumento aconteceu em pH alcalino. }\end{array}$ & $\begin{array}{c}\text { Singh, Jajoo e Bhasin } \\
(2020)\end{array}$ \\
\hline
\end{tabular}


Research, Society and Development, v. 10, n. 7, e6210716240, 2021

(CC BY 4.0) | ISSN 2525-3409 | DOI: http://dx.doi.org/10.33448/rsd-v10i7.16240

A imobilização de enzimas em partículas trata-se de uma separação física entre a enzima e o ambiente reacional através do uso de polímeros como uma estratégica para conduzir a reação de forma mais direcionada aos objetivos de produção, podendo ser encontrada de duas formas: a imobilização das partículas na parede do reator ou dentro de um tubo para operações em leito fixo (Romero-Fernández \& Paradisi, 2020). Permite a melhora na eficiência de transferência de massa, minimização de problemas de difusão, aumento da razão entre superfície e volume, carregamento efetivo de enzimas, condução de reações em fluxo contínuo, além de propor alternativas não químicas para as reações dentro da indústria (Wong, Tan, Lau, Yap \& Danquah, 2019).

Entretanto, as pesquisas ainda enfrentam dificuldades relacionadas ao escalonamento partindo de testes laboratoriais a nível industrial, como também problemas de conformação enzimática quando ocorre interação entre a enzima e a matriz selecionada ou quando a mesma age como uma barreira de acesso aos substratos, este não conseguindo atravessar os poros da matriz encapsulante para o acesso do sítio catalítico (Wong, et al., 2019). O mesmo se reflete caso sejam formados produtos da reação que também encontrem dificuldades de difusão para fora da partícula, por isto a importância da seleção e estudos de polímeros eficientes para revestir a enzima.

Outra solução proposta é que enzimas imobilizadas podem ser aplicadas na bioconversão de resíduos alimentares em produtos de alto valor. São resíduos do processamento ricos em carboidratos, proteínas e lipídios que são convertidos em biocombustíveis, materiais plásticos biodegradáveis, compostos de ação bioativa e probióticos, que além de reduzir o que seria destinado a aterros estará gerando maior economia e lucro no ciclo produtivo (Bilal \& Iqbal, 2019).

Já os PCM's são substâncias que apresentam duas formas de rearranjo, uma cristalina e outra amorfa, podendo constantemente trocar de um modelo para outro permitindo que ocorra o armazenamento e liberação de energia. Quando passam por essa mudança, a modificação da fase amorfa para cristalina ocorre quando o material é aquecido acima da temperatura de cristalização. Entre os benefícios de sua utilização estão a alta capacidade de armazenamento energético, baixo custo, não corrosividade, alta estabilidade química e possibilidade de liberação de energia em condições ajustáveis (Alehosseini \& Jafari, 2019). Permitem, portanto, a maior manutenção da temperatura em sistemas de armazenamento, tanto em câmaras térmicas (Wang, Yu, Li \& Zhao, 2016) ou em embalagens a qual está transportando o alimento (Chalco-Sandoval, et al., 2017).

Além do uso de PCM em embalagens também podemos encontrar antimicrobianos naturais em embalagens, como no estudo de Chen, Li, Ma, Mcdonald e Wang (2019) que encapsularam pela técnica de complexação de inclusão molecular o citral e o trans-cinemaldeído obtendo a extensão do tempo de prateleira de carne bovina resfriada $\left(4^{\circ} \mathrm{C}\right) \mathrm{em}$ quatro dias. $\mathrm{No}$ trabalho de Bruni et al. (2020) que encapsularam o $\beta$-caroteno por eletrofiação utilizando como materiais de parede o isolado proteico da soja e o álcool polivinílico a qual foi diretamente formado no filme de polihidroxibutirato-co-valerato (PHB92/PHV8), obtendo no final 51,4\% de eficiência de encapsulamento, destinado a ação antioxidante de uma embalagem para produtos alimentícios.

O uso de encapsulados dentro da indústria de alimentos vem crescendo e favorecendo vantagens no aprimoramento de processos e produtos que incentivam o aumento de pesquisas na área. Já existem materiais biológicos (enzimas e microrganismos) dentro das operações unitárias nas indústrias de alimentos, aspecto que motiva a necessidade de otimizações, a qual as tecnologias de encapsulamento atendem. possa impulsionar o desenvolvimento de novas formas de aplicações. 


\section{Conclusão}

Atualmente, o que entendemos como Tecnologia de Encapsulamento, surgiu da observação do comportamento estrutural biológico de sucesso da membrana plasmática de células e da repetição de sua proposta de funcionalidade para a proteção de agente ativos sensíveis a múltiplos fatores. Diversos pesquisadores realizaram o aperfeiçoamento contínuo das formas as quais podemos realizar o envelopamento de agentes ativos, o entendimento de como otimizar o processo considerando as características individuais dos materiais utilizados e o destino requerido. Dessa forma, novos usos aplicáveis de encapsulamento além da sua utilização como tecnologia de conservação foram surgindo, como um meio de veiculação inteligente de bioativos em diversas matrizes bem como no organismo humano e estratégia para melhorias ativas dentro do meio industrial.

No que se refere ao setor de alimentos, algumas macromoléculas potenciais devido a sua suscetibilidade à perda de características desejáveis por conta de ações biológicas, químicas e ambientais tem a sua exploração dificultada. O encapsulamento se torna um meio viável para contornar a incidência de efeitos deletérios sobre essas substâncias e, consequentemente, aumentar a faixa de aplicação.

Estas aplicações estão constantemente avançando, saindo dos testes conformacionais da partícula e tendo seu comportamento analisado dentro de matrizes complexas, como os alimentos, onde estão presentes diversas moléculas que podem agir de forma benéfica ou não na veiculação de particulados. Testes em amostras reais são importantes para formar o arcabouço de novos estudos e incentivar a discussão de métodos escalonáveis do preparo de materiais encapsulados a nível industrial. O encapsulamento age como um método para o surgimento e desenvolvimento de novos aditivos e participa das operações unitárias que dão origem aos produtos, participando também de diversos processos da dinâmica industrial, como o tratamento de efluentes, higienização, economia energética nas operações térmicas e a redução de resíduos gerados pela transformação destes em novos produtos de valor comercial.

Existem ainda desafios a serem resolvidos, como a adequação dos métodos de encapsulamento a escala industrial, e identificados no decorrer das pesquisas no segmento, no entanto, a utilização de partículas dentro do ramo alimentício é crescente e não levará muito tempo para observarmos mais produtos nas prateleiras dos supermercados com a tecnologia de encapsulamento inclusa. Para trabalhos futuros em um cenário a qual as pesquisas e literatura avancem com mais estudos de aplicação da Tecnologia de Encapsulamento sugere-se que venha a surgir uma revisão que possa explorar mais aprofundado a relação dos encapsulados dentro de matrizes alimentícias.

\section{Referências}

Aguilera, J. M. (2018). Engenharia de alimentos no século XXI. AlChE Journal, 64 (1), 2-11.

Alagha, M. S., \& Szentannai, P. (2020). Analytical review of fluid-dynamic and thermal modeling aspects of fluidized beds for energy conversion devices. International Journal of Heat and Mass Transfer, 147, 118907.

Alehosseini, E., \& Jafari, S. M. (2019). Micro/nano-encapsulated phase change materials (PCMs) as emerging materials for the food industry. Trends in Food Science and Technology, 91, 116-128.

Alexandre, J. de B., Barroso, T. L. C. T., Oliveira, M. de A., Mendes, F. R. da S., da Costa, J. M. C., Moreira, R. de A., \& Furtado, R. F. (2019). Cross-linked coacervates of cashew gum and gelatin in the encapsulation of pequi oil. Ciencia Rural, 49(12), 20190079.

Azeredo, H. M. C. de (2005). Encapsulação: aplicação à tecnologia de alimentos. Alimentos e Nutrição, 16(1), 89-97.

Bartkiene, E., Zavistanaviciute, P., Lele, V., Ruzauskas, M., Bartkevics, V., Bernatoniene, J., Gallo, P., Tenore, G. C., \& Santini, A. (2018). Lactobacillus plantarum LUHS135 and paracasei LUHS244 as functional starter cultures for the food fermentation industry: Characterisation, mycotoxin-reducing properties, optimisation of biomass growth and sustainable encapsulation by using dairy by-produc. Lwt, 93(March), 649-658.

Bastos, L. P. H., Vicente, J., Santos, C. H. C. dos, Carvalho, M. G. de, \& Garcia-Rojas, E. E. (2020). Encapsulation of black pepper (Piper nigrum L.) essential oil with gelatin and sodium alginate by complex coacervation. Food Hydrocolloids, 102(September 2019), 105605. 
Research, Society and Development, v. 10, n. 7, e6210716240, 2021

(CC BY 4.0) | ISSN 2525-3409 | DOI: http://dx.doi.org/10.33448/rsd-v10i7.16240

Belostozky, A., Bretler, S., Kolitz-Domb, M., Grinberg, I., \& Margel, S. (2019). Solidification of oil liquids by encapsulation within porous hollow silica microspheres of narrow size distribution for pharmaceutical and cosmetic applications. Materials Science and Engineering C, 97(December 2018), 760-767.

Benelli, L., \& Oliveira, W. P. (2019). Fluidized bed coating of inert cores with a lipid-based system loaded with a polyphenol-rich Rosmarinus officinalis extract. Food and Bioproducts Processing, 114, 216-226.

Besselink, M. G., Santvoort, H. C., Buskens, E. van, Boermeester, M. A., Goor, H. van, Timmerman, H. M., Nieuwenhuijs, V. B., Bollen, T. L., Ramshorst, B. van, Witteman, B. J., Rosman, C., Ploeg, R. J., Brink, M. A., Schaapherder, A. F., Dejong, C. H., Wahab, P. J., Laarhoven, C. J. van, Harst, E. van der, Eijck, C. H. van, Cuesta, M. G., Akkermans, L. M. A., \& Gooszen, H. G. (2008). Probiotic prophylaxis in predicted severe acute pancreatitis: a randomised, doubleblind, placebo-controlled trial. The Lancet, 371(9613), 651-659.

Bilal, M., \& Iqbal, H. M. N. (2019). Sustainable bioconversion of food waste into high-value products by immobilized enzymes to meet bio-economy challenges and opportunities - A review. Food Research International, 123(April), 226-240.

Bilek, S. E., Y1lmaz, F. M., \& Özkan, G. (2017). The effects of industrial production on black carrot concentrate quality and encapsulation of anthocyanins in whey protein hydrogels. Food and Bioproducts Processing, 102, 72-80.

Blenford, D. (1986). Food, flavourings, ingredients, processing. Packaging, 8, (7), 43.

Bruni, G. P., Oliveira, J. P. de, Gómez-Mascaraque, L. G., Fabra, M. J., Martins, V. G., Zavareze, E. da R., \& López-Rubio, A. (2020). Electrospun $\beta$ carotene-loaded SPI:PVA fiber mats produced by emulsion-electrospinning as bioactive coatings for food packaging. Food Packaging and Shelf Life, 23(January 2019), 100426.

Burgos-Díaz, C., Hernández, X., Wandersleben, T., Barahona, T., Medina, C., Quiroz, A., \& Rubilar, M. (2018). Influence of multilayer O/W emulsions stabilized by proteins from a novel lupin variety AluProt-CGNA and ionic polysaccharides on D-limonene retention during spray-drying. Colloids and Surfaces A: Physicochemical and Engineering Aspects, 536(October 2016), 234-241.

Cacciatore, F. A., Dalmás, M., Maders, C., Ataíde Isaía, H., Brandelli, A., \& Silva Malheiros, P. da (2020). Carvacrol encapsulation into nanostructures: Characterization and antimicrobial activity against foodborne pathogens adhered to stainless steel. Food Research International, 133 (March), 109143.

Chalco-Sandoval, W., Fabra, M. J., López-Rubio, A., \& Lagaron, J. M. (2015). Optimization of solvents for the encapsulation of a phase change material in polymeric matrices by electro-hydrodynamic processing of interest in temperature buffering food applications. European Polymer Journal, 72, $23-33$.

Chalco-Sandoval, W., Fabra, M. J., López-Rubio, A., \& Lagaron, J. M. (2017). Use of phase change materials to develop electrospun coatings of interest in food packaging applications. Journal of Food Engineering, 192, 122-128.

Chan, E. S., Wong, S. L., Lee, P. P., Lee, J. S., Ti, T. B., Zhang, Z., Poncelet, D., Ravindra, P., Phan, S. H., \& Yim, Z. H. (2011). Effects of starch filler on the physical properties of lyophilized calcium-alginate beads and the viability of encapsulated cells. Carbohydrate Polymers, 83(1), 225-232.

Chan, L. W., Lee, H. Y., \& Heng, P. W. S. (2006). Mechanisms of external and internal gelation and their impact on the functions of alginate as a coat and delivery system. Carbohydrate Polymers, 63(2), 176-187.

Chen, H., Li, L., Ma, Y., Mcdonald, T. P., \& Wang, Y. (2019). Development of active packaging film containing bioactive components encapsulated in $\beta$ cyclodextrin and its application. Food Hydrocolloids, 90(December 2018), 360-366.

Chen, S., Zhang, Y., Han, Y., McClements, D. J., Liao, W., Mao, L., Yuan, F., \& Gao, Y. (2020). Fabrication of multilayer structural microparticles for coencapsulating coenzyme Q10 and piperine: Effect of the encapsulation location and interface thickness. Food Hydrocolloids, 109(17), 106090.

Comunian, T. A., Chaves, I. E., Thomazini, M., Moraes, I. C. F., Ferro-Furtado, R., Castro, I. A. de, \& Favaro-Trindade, C. S. (2017). Development of functional yogurt containing free and encapsulated echium oil, phytosterol and sinapic acid. Food Chemistry, 237, 948-956.

Comunian, T. A., Silva, M. P., Moraes, I. C. F., \& Favaro-Trindade, C. S. (2020). Reducing carotenoid loss during storage by co-encapsulation of pequi and buriti oils in oil-in-water emulsions followed by freeze-drying: Use of heated and unheated whey protein isolates as emulsifiers. Food Research International, 130(December 2019), 108901.

Dag, D., Guner, S., \& Oztop, M. H. (2019). Physicochemical mechanisms of different biopolymers' (lysozyme, gum arabic, whey protein, chitosan) adsorption on green tea extract loaded liposomes. International Journal of Biological Macromolecules, 138, 473-482.

Delshadi, R., Bahrami, A., Tafti, A. G., Barba, F. J., \& Williams, L. L. (2020). Micro and nano-encapsulation of vegetable and essential oils to develop functional food products with improved nutritional profiles. Trends in Food Science \& Technology, 104 (October 2020), $72-83$.

Dhillon, P., Singh, K., \& Kaur, K. (2020). The benefits of probiotic interventions in maternal-fetal health: An appraise review. PharmaNutrition, 13(May), 100211.

Eghbal, N., \& Choudhary, R. (2018). Complex coacervation: Encapsulation and controlled release of active agents in food systems. LWT - Food Science and Technology, 90(December 2017), 254-264.

Fang, S., Zhao, X., Liu, Y., Liang, X., \& Yang, Y. (2019). Fabricating multilayer emulsions by using OSA starch and chitosan suitable for spray drying: Application in the encapsulation of $\beta$-carotene. Food Hydrocolloids, 93(May 2018), 102-110.

FAO/WHO/UNU (2001). Human energy requirements. Report of a joint FAO/WHO/UNU expert consultation. Rome: Food and Agriculture Organization. Favaro-Trindade, C. S., Pinho, S. C., \& Rocha, G. A. (2008). Revisão: Microencapsulação de ingredientes alimentícios. Brazilian Journal of Food Tecnology, 11(2), 103-112. 
Research, Society and Development, v. 10, n. 7, e6210716240, 2021

(CC BY 4.0) | ISSN 2525-3409 | DOI: http://dx.doi.org/10.33448/rsd-v10i7.16240

Fernando, I. P. S., Lee, W. W., Han, E. J., \& Ahn, G. (2020). Alginate-based nanomaterials: Fabrication techniques, properties, and applications. Chemical Engineering Journal, 391(July 2019), 123823.

Ferreira, S., \& Nicoletti, V. R. (2021). Microencapsulation of ginger oil by complex coacervation using atomization: Effects of polymer ratio and wall material concentration. Journal of Food Engineering, 291(July 2020), 110214.

Geranpour, M., Assadpour, E., \& Jafari, S. M. (2020). Recent advances in the spray drying encapsulation of essential fatty acids and functional oils. Trends in Food Science and Technology, 102(January), 71-90.

Giacometti, J., Bursać Kovačević, D., Putnik, P., Gabrić, D., Bilušić, T., Krešić, G., Stulić, V., Barba, F. J., Chemat, F., Barbosa-Cánovas, G., \& Režek Jambrak, A. (2018). Extraction of bioactive compounds and essential oils from mediterranean herbs by conventional and green innovative techniques: A review. Food Research International, 113(June), 245-262.

Gomez-Estaca, J., Comunian, T. A., Montero, P., Ferro-Furtado, R., \& Favaro-Trindade, C. S. (2016). Encapsulation of an astaxanthin-containing lipid extract from shrimp waste by complex coacervation using a novel gelatin-cashew gum complex. Food Hydrocolloids, 61, 155-162.

Gómez-Mascaraque, L. G., Hernández-Rojas, M., Tarancón, P., Tenon, M., Feuillère, N., Vélez Ruiz, J. F., Fiszman, S., \& López-Rubio, A. (2017). Impact of microencapsulation within electrosprayed proteins on the formulation of green tea extract-enriched biscuits. LWT - Food Science and Technology, 81, 77-86.

Griffin, K., \& Khouryieh, H. (2020). Influence of electrostatic interactions on the formation and stability of multilayer fish oil-in-water emulsions stabilized by whey protein-xanthan-locust bean complexes. Journal of Food Engineering, 277(September 2019), 109893.

Haas, K., Dohnal, T., Andreu, P., Zehetner, E., Kiesslich, A., Volkert, M., Fryer, P., \& Jaeger, H. (2020). Particle engineering for improved stability and handling properties of carrot concentrate powders using fluidized bed granulation and agglomeration. Powder Technology, 370, 104-115.

Haghighat-Kharazi, S., Jafar, M. M., Kasaai, M. R., \& Khajeh, K. (2019). Use of encapsulated maltogenic amylase in malotodextrins with different formulations in making gluten-free breads. Lwt, 110(November 2018), 182-189.

Han, S., Chen, Y., Lyu, S., Chen, Z., Wang, S., \& Fu, F. (2020). Effects of processing conditions on the properties of paraffin/melamine-urea-formaldehyde microcapsules prepared by in situ polymerization. Colloids and Surfaces A: Physicochemical and Engineering Aspects, 585(September 2019$), 124046$.

Hernández-Barrueta, T., Martínez-Bustos, F., Castaño-Tostado, E., Lee, Y., Miller, M. J., \& Amaya-Llano, S. L. (2020). Encapsulation of probiotics in whey protein isolate and modified huauzontle's starch: An approach to avoid fermentation and stabilize polyphenol compounds in a ready-to-drink probiotic green tea. Lwt, 124(January), 109131.

Hernández-Nava, R., López-Malo, A., Palou, E., Ramírez-Corona, N., \& Jiménez-Munguía, M. T. (2020). Encapsulation of oregano essential oil (Origanum vulgare) by complex coacervation between gelatin and chia mucilage and its properties after spray drying. Food Hydrocolloids, 109 (January), 106077.

Hu, J., Zhang, Y., Xiao, Z., \& Wang, X. (2018). Preparation and properties of cinnamon-thyme-ginger composite essential oil nanocapsules. Industrial Crops and Products, 122(October 2017), 85-92.

Hu, Y., Shu, J., Zhang, X., Zhao, A., Liu, Y., Li, R., Di, Y., Xu, H., \& Gan, Z. (2020). Encapsulation of colloid perovskite nanocrystals into solid polymer matrices: Impact on electronic transition and photoluminescence. Journal of Luminescence, 219(July 2019), 116938.

Islam, M., Mahmud, N., Nawas, T., Fang, Y., \& Xia, W. (2018). Health Benefits and Spray Drying Microencapsulation Process of Fish Oil (Omega-3). American Journal of Food Science and Nutrition Research, 5(2), 29.

Jamshidi, A., Cao, H., Xiao, J., \& Simal-Gandara, J. (2020). Advantages of techniques to fortify food products with the benefits of fish oil. Food Research International, 137(January), 109353.

Jiang, G. L., \& Zhu, M. J. (2019). Preparation of astaxanthin-encapsulated complex with zein and oligochitosan and its application in food processing. Lwt, 106(October 2018), 179-185.

Kailasapathy, K., \& Lam, S. H. (2005). Application of encapsulated enzymes to accelerate cheese ripening. International Dairy Journal, 15(6-9), 929-939.

Kamanina, O. A., Lavrova, D. G., Arlyapov, V. A., Alferov, V. A., \& Ponamoreva, O. N. (2016). Silica sol-gel encapsulated methylotrophic yeast as filling of biofilters for the removal of methanol from industrial wastewater. Enzyme and Microbial Technology, 92, 94-98.

Kim, E. H. J., Paredes, D., Motoi, L., Eckert, M., Wadamori, Y., Tartaglia, J., Green, C., Hedderley, D. I., \& Morgenstern, M. P. (2019). Dynamic flavor perception of encapsulated flavors in a soft chewable matrix. Food Research International, 123(December 2018), 241-250.

Kim, J. G., Lee, E., Kim, S. H., Whang, K. Y., Oh, S., \& Imm, J. Y. (2009). Effects of a Lactobacillus casei 393 fermented milk product on bone metabolism in ovariectomised rats. International Dairy Journal, 19(11), 690-695.

Kim, Y. A., Keogh, J. B., \& Clifton, P. M. (2018). Probiotics, prebiotics, synbiotics and insulin sensitivity. Nutrition Research Reviews, 31 (1), $35-51$.

Kurozawa, L. E., \& Hubinger, M. D. (2017). Hydrophilic food compounds encapsulation by ionic gelation. Current Opinion in Food Science, 15, $50-55$.

Lehmann, S. E., Hartge, E. U., Jongsma, A., deLeeuw, I. M., Innings, F., \& Heinrich, S. (2019). Fluidization characteristics of cohesive powders in vibrated fluidized bed drying at low vibration frequencies. Powder Technology, 357, 54-63.

Li, K., Wang, B., Wang, W., Liu, G., Ge, W., Zhang, M., Yue, B., \& Kong, M. (2019). Microencapsulation of Lactobacillus casei BNCC 134415 under lyophilization enhances cell viability during cold storage and pasteurization, and in simulated gastrointestinal fluids. Lwt, 116(July), 108521 
Research, Society and Development, v. 10, n. 7, e6210716240, 2021

(CC BY 4.0) | ISSN 2525-3409 | DOI: http://dx.doi.org/10.33448/rsd-v10i7.16240

Li, T., Teng, D., Mao, R., Hao, Y., Wang, X., \& Wang, J. (2020). A critical review of antibiotic resistance in probiotic bacteria. Food Research International, 136(July), 109571.

Librán, C. M., Castro, S., \& Lagaron, J. M. (2017). Encapsulation by electrospray coating atomization of probiotic strains. Innovative Food Science and Emerging Technologies, 39, 216-222.

Liu, C., Tan, Y., Xu, Y., McCleiments, D. J., \& Wang, D. (2019). Formation, characterization, and application of chitosan/pectin-stabilized multilayer emulsions as astaxanthin delivery systems. International Journal of Biological Macromolecules, 140, 985-997.

Long, J., Pan, T., Xie, Z., Xu, X., \& Jin, Z. (2020). Co-immobilization of $\beta$-fructofuranosidase and glucose oxidase improves the stability of Bi-enzymes and the production of lactosucrose. Lwt, 128(April 2019), 109460.

Lu, Y., Xiao, X., Liu, Y., Wang, J., Qi, S., Huan, C., Liu, H., Zhu, Y., \& Xu, G. (2020). Achieving multifunctional smart textile with long afterglow and thermo-regulation via coaxial electrospinning. Journal of Alloys and Compounds, 812, 152144.

Malar, C. G., Seenuvasan, M., Kumar, K. S., Kumar, A., \& Parthiban, R. (2020). Review on surface modification of nanocarriers to overcome diffusion limitations: An enzyme immobilization aspect. Biochemical Engineering Journal, 158(March), 10754.

Martins, N., Roriz, C. L., Morales, P., Barros, L., \& Ferreira, I. C. F. R. (2016). Food colorants: Challenges, opportunities and current desires of agroindustries to ensure consumer expectations and regulatory practices. Trends in Food Science and Technology, 52, 1-15.

Menin, A., Zanoni, F., Vakarelova, M., Chignola, R., Donà, G., Rizzi, C., Mainente, F., \& Zoccatelli, G. (2018). Effects of microencapsulation by ionic gelation on the oxidative stability of flaxseed oil. Food Chemistry, 269(June), 293-299.

Michalska, A., \& Lech, K. (2018). The Effect of Carrier Quantity and Drying Method on the Physical Properties of Apple Juice Powders. Beverages, 4(2), 115 .

Microencapsulação. (2017). A tecnologia da microencapsulação de ingredientes. Food Ingredients Brasil, (42), 18-26.

Mogensen, K. M. (2017). Essential fatty acid deficiency. Practical Gastroenterology, 41(6), 37-44.

Mörschbächer, A. P., Volpato, G., \& Souza, C. F. V. de. (2016). Kluyveromyces lactis $\beta$-galactosidase immobilization in calcium alginate spheres and gelatin for hydrolysis of cheese whey lactose. Ciência Rural, 46(5), 921-926.

Moura, S. C. S. R. de, Berling, C. L., Garcia, A. O., Queiroz, M. B., Alvim, I. D., \& Hubinger, M. D. (2019). Release of anthocyanins from the hibiscus extract encapsulated by ionic gelation and application of microparticles in jelly candy. Food Research International, 121(December 2018), 542-552.

Muriel Mundo, J. L., Zhou, H., Tan, Y., Liu, J., \& McClements, D. J. (2020). Stabilization of soybean oil-in-water emulsions using polypeptide multilayers: Cationic polylysine and anionic polyglutamic acid. Food Research International, 137(May), 109304.

Nascimento, M. A. do, Silva, L. C. da, Mendes, L. G., Furtado, R. F., Costa, J. M. C. da, Biswas, A., Cheng, H. N., \& Alves, C. R. (2020). Pequi oil microencapsulation by complex coacervation using gelatin-cashew gum. International Journal of Food Studies, 9(2020), 97-109.

Nguon, O., Lagugné-Labarthet, F., Brandys, F. A., Li, J., \& Gillies, E. R. (2018). Microencapsulation by in situ Polymerization of Amino Resins. Polymer Reviews, 58(2), 326-375.

Nikoo, A. M., Kadkhodaee, R., Ghorani, B., Razzaq, H., \& Tucker, N. (2018). Electrospray-assisted encapsulation of caffeine in alginate microhydrogels. International Journal of Biological Macromolecules, 116, 208-216.

Niu, B., Shao, P., Luo, Y., \& Sun, P. (2020). Recent advances of electrosprayed particles as encapsulation systems of bioactives for food application. Food Hydrocolloids, 99(September 2019), 105376.

Oliveira, W. Q. de, Wurlitzer, N. J., Araújo, A. W. de O., Comunian, T. A., Bastos, M. do S. R., Oliveira, A. L. de, Magalhães, H. C. R., Ribeiro, H. L., Figueiredo, R. W. de, \& Sousa, P. H. M. de (2020). Complex coacervates of cashew gum and gelatin as carriers of green coffee oil: The effect of microcapsule application on the rheological and sensorial quality of a fruit juice. Food Research International, 131(October 2019), 109047.

Ozkan, G., Franco, P., Marco, I. de, Xiao, J., \& Capanoglu, E. (2019). A review of microencapsulation methods for food antioxidants: Principles, advantages, drawbacks and applications. Food Chemistry, 272(July 2018), 494-506.

Petito, N. de L., Dias, D. da S., Costa, V. G., Falcão, D. Q., \& Araujo, K. G. de Lima. (2016). Increasing solubility of red bell pepper carotenoids by complexation with 2-hydroxypropyl- $\beta$-cyclodextrin. Food Chemistry, 208, 124-131.

Quigley, E. M. M. (2019). Prebiotics and Probiotics in Digestive Health. Clinical Gastroenterology and Hepatology, 17(2), 333-344.

Radünz, M., Hackbart, H. C. dos S., Camargo, T. M., Nunes, C. F. P., Barros, F. A. P., Magro, J. D., Sanches Filho, P. J., Gandra, E. A., \& Zavareza, E. da R. (2020). Antimicrobial potential of spray drying encapsulated thyme (Thymus vulgaris) essential oil on the conservation of hamburger-like meat products. International Journal of Food Microbiology, 330, 108696.

Rahim, S. N. A., Sulaiman, A., Hamzah, F., Hamid, K. H. K., Rodhi, M. N. M., Musa, M., \& Edama, N. A. (2013). Enzymes encapsulation within calcium alginate-clay beads: Characterization and application for cassava slurry saccharification. Procedia Engineering, 68, 411-417.

Rajkumar, V., Gunasekaran, C., Paul, C. A., \& Dharmaraj, J. (2020). Development of encapsulated peppermint essential oil in chitosan nanoparticles: Characterization and biological efficacy against stored-grain pest control. Pesticide Biochemistry and Physiology, 170(November 2020), 104679.

Ré, M. I. (2000). Microencapsulação: Em busca de produtos inteligentes. Ciência Hoje, 27(162), 24-29. 
Research, Society and Development, v. 10, n. 7, e6210716240, 2021

(CC BY 4.0) | ISSN 2525-3409 | DOI: http://dx.doi.org/10.33448/rsd-v10i7.16240

Rios-Mera, J. D., Saldaña, E., Ramírez, Y., Auquiñivín, E. A., Alvim, I. D., \& Contreras-Castillo, C. J. (2019). Encapsulation optimization and pH- and temperature-stability of the complex coacervation between soy protein isolate and inulin entrapping fish oil. Lwt, 116(March), 108555.

Rodrigues, R. M., Ramos, P. E., Cerqueira, M. F., Teixeira, J. A., Vicente, A. A., Pastrana, L. M., Pereira, R. N., \& Cerqueira, M. A. (2020). Electrosprayed whey protein-based nanocapsules for $\beta$-carotene encapsulation. Food Chemistry, 314(January), 126157.

Romero-Fernández, M., \& Paradisi, F. (2020). Protein immobilization technology for flow biocatalysis. Current Opinion in Chemical Biology, 55, 1-8.

Ruiz, J. C. R., Vazquez, E. D. L. L. O., \& Campos, M. R. S. (2017). Encapsulation of vegetable oils as source of omega-3 fatty acids for enriched functional foods. Critical Reviews in Food Science and Nutrition, 57(7), 1423-1434.

Rutz, J. K., Borges, C. D., Zambiazi, R. C., Crizel-Cardozo, M. M., Kuck, L. S., \& Noreña, C. P. Z. (2017). Microencapsulation of palm oil by complex coacervation for application in food systems. Food Chemistry, 220, 59-66.

Saifullah, M., Shishir, M. R. I., Ferdowsi, R., Rahman, R. T., \& Vuong, Q. van (2019). Micro and nano encapsulation, retention and controlled release of flavor and aroma compounds: A critical review. Trends in Food Science and Technology, 86(September 2018), 230-251.

Sharma, S., Cheng, S. F., Bhattacharya, B., \& Chakkaravarthi, S. (2019). Efficacy of free and encapsulated natural antioxidants in oxidative stability of edible oil: Special emphasis on nanoemulsion-based encapsulation. Trends in Food Science and Technology, 91(August 2018), 305-318.

Shishir, M. R. I., \& Chen, W. (2017). Trends of spray drying: A critical review on drying of fruit and vegetable juices. Trends in Food Science and Technology, 65, 49-67.

Shishir, M. R. I., Taip, F. S., Saifullah, M., Aziz, N. A., \& Talib, R. A. (2017). Effect of packaging materials and storage temperature on the retention of physicochemical properties of vacuum packed pink guava powder. Food Packaging and Shelf Life, 12(October 2016), 83-90.

Shishir, M. R. I., Xie, L., Sun, C., Zheng, X., \& Chen, W. (2018). Advances in micro and nano-encapsulation of bioactive compounds using biopolymer and lipid-based transporters. Trends in Food Science and Technology, 78(May), 34-60.

Silva, L. C. da, Nascimento, M. A. do, Mendes, L. G., Furtado, R. F., Costa, J. M. C. da, \& Cardoso, A. L. H (2017). Optimization of cashew gum and chitosan for microencapsulation of pequi oil by complex coacervation. Journal of Food Processing and Preservation, 42(3), 1-8.

Singh, T. A.; Jajoo, A., \& Bhasin, S. (2020). Optimization of various encapsulation systems for efficient immobilization of actinobacterial glucose isomerase. Biocatalysis and Agricultural Biotechnology, 29(October 2020), 101766.

Souza Simões, L. de, Madalena, D. A., Pinheiro, A. C., Teixeira, J. A., Vicente, A. A., \& Ramos, Ó. L. (2017). Micro- and nano bio-based delivery systems for food applications: In vitro behavior. Advances in Colloid and Interface Science, 243, 23-45.

Suave, J., Dall'agnol, E. C., Pezzin, A. T. T., Silva, D. A. K., Meirer, M. M., \& Soldi, V. (2006). Microencapsulação: Inovação em diferentes áreas. Revista Saúde e Ambiente / Health and Environment Journal, 7(2), 12-20.

Sultana, A., Miyamoto, A., Lan Hy, Q., Tanaka, Y., Fushimi, Y., \& Yoshii, H. (2017). Microencapsulation of flavors by spray drying using Saccharomyces cerevisiae. Journal of Food Engineering, 199, 36-41.

Taban, A., Saharkhiz, M. J., \& Khorram, M. (2020). Formulation and assessment of nano-encapsulated bioherbicides based on biopolymers and essential oil. Industrial Crops and Products, 149 (January), 112348.

Tallima, H., \& El Ridi, R. (2018). Arachidonic acid: Physiological roles and potential health benefits - A review. Journal of Advanced Research, $11,33-41$.

Tang, Y., Scher, H. B., \& Jeoh, T. (2020). Industrially scalable complex coacervation process to microencapsulate food ingredients. Innovative Food Science and Emerging Technologies, 59(June 2019), 102257.

Timilsena, Y. P., Akanbi, T. O., Khalid, N., Adhikari, B., \& Barrow, C. J. (2019). Complex coacervation: Principles, mechanisms and applications in microencapsulation. International Journal of Biological Macromolecules, 121, 1276-1286.

Trucillo, P., Campardelli, R., \& Reverchon, E. (2018). Production of liposomes loaded with antioxidants using a supercritical CO2 assisted process. Powder Technology, 323, 155-162.

UNESP. (2015). Tipos de Revisão de Literatura. Recuperado em 29 maio, 2021, de https://docplayer.com.br/12500538-Tipos-de-revisao-de-literatura.html

Valldeperas, M., Salis, A., Barauskas, J., Tiberg, F., Arnebrant, T., Razumas, V., Monduzzi, M., \& Nylander, T. (2019). Enzyme encapsulation in nanostructured self-assembled structures: Toward biofunctional supramolecular assemblies. Current Opinion in Colloid and Interface Science, $44,130-142$.

Vinceković, M., Viskić, M., Jurić, S., Giacometti, J., Bursać Kovačević, D., Putnik, P., Donsì, F., Barba, F. J., \& Režek Jambrak, A. (2017). Innovative technologies for encapsulation of Mediterranean plants extracts. Trends in Food Science and Technology, 69, 1-12.

Wang, X., Yu, H., Li, L., \& Zhao, M. (2016). Research on temperature dependent effective thermal conductivity of composite-phase change materials (PCMs) wall based on steady-state method in a thermal chamber. Energy and Buildings, 26(August 2016), 408-414.

Waterhouse, G. I. N., \& Sun-Waterhouse, D. (2019). Encapsulation systems containing multi-nutrients/bioactives: From molecular scale to industrial scale. In Encyclopedia of Food Chemistry, 687-694.

Wen, P., Zong, M. H., Linhardt, R. J., Feng, K., \& Wu, H. (2017). Electrospinning: A novel nano-encapsulation approach for bioactive compounds. Trends in Food Science and Technology, 70(July), 56-68. 
Research, Society and Development, v. 10, n. 7, e6210716240, 2021

(CC BY 4.0) | ISSN 2525-3409 | DOI: http://dx.doi.org/10.33448/rsd-v10i7.16240

Wilkerson, J. W., Yang, S. O., Funk, P. J., Stanley, S. K., \& Bundy, B. C. (2018). Nanoreactors: Strategies to encapsulate enzyme biocatalysts in virus-like particles. New Biotechnology, 44(September 2017), 59-63.

Wong, J. K. H., Tan, H. K., Lau, S. Y., Yap, P. S., \& Danquah, M. K. (2019). Potential and challenges of enzyme incorporated nanotechnology in dye wastewater treatment: A review. Journal of Environmental Chemical Engineering, 7(4), 103261.

Xiao, Z., Hou, W., Kang, Y., Niu, Y., \& Kou, X. (2019). Encapsulation and sustained release properties of watermelon flavor and its characteristic aroma compounds from $\gamma$-cyclodextrin inclusion complexes. Food Hydrocolloids, 97(100), 105202.

Yan, L., Wang, R., Wang, H., Sheng, K., Liu, C., Qu, H., Ma, A., \& Zheng, L. (2018). Formulation and characterization of chitosan hydrochloride and carboxymethyl chitosan encapsulated quercetin nanoparticles for controlled applications in foods system and simulated gastrointestinal condition. Food Hydrocolloids, 84(June), 450-457.

Yin, Y., \& Cadwallader, K. R. (2019). Spray-chilling encapsulation of 2-acetyl-1-pyrroline zinc chloride using hydrophobic materials: Storage stability and flavor application in food. Food Chemistry, 278(December 2018), 738-743.

Zaeim, D., Sarabi-Jamab, M., Ghorani, B., Kadkhodaee, R., \& Tromp, R. H. (2017). Electrospray assisted fabrication of hydrogel microcapsules by singleand double-stage procedures for encapsulation of probiotics. Food and Bioproducts Processing, 102, 250-259.

Zambrano-Zaragoza, M. L., \& Quintanar-Guerrero, D. (2019). Novel techniques for extrusion, agglomeration, encapsulation, gelation, and coating of foods. Encyclopedia of Food Security and Sustainability, 1, 379-392.

Zhang, R., Belwal, T., Li, L., Lin, X., Xu, Y., \& Luo, Z. (2020). Recent advances in polysaccharides stabilized emulsions for encapsulation and delivery of bioactive food ingredients: A review. Carbohydrate Polymers, 242(January), 116388.

Zhang, Y., Mustapha, A. N., Zhang, X., Baiocco, D., Wellio, G., Davies, T., Zhang, Z., \& Li, Y. (2020). Improved volatile cargo retention and mechanical properties of capsules via sediment-free in situ polymerization with cross-linked poly(vinyl alcohol) as an emulsifier. Journal of Colloid and Interface Science, 568(June 2019), 155-164.

Zhou, D., Pan, Y., Ye, J., Jia, J., Ma, J., \& Ge, F. (2017). Preparation of walnut oil microcapsules employing soybean protein isolate and maltodextrin with enhanced oxidation stability of walnut oil. LWT - Food Science and Technology, 83, 292-297. 